\title{
UC-4
}

Issued: June 1985

LA -10340

DE85 015368

\section{Experimentai Studies of Actinides in Molten Salts}

\author{
James G. Reavis
}

\author{
DISCLAIMER
}

This report was prepared as an account of work sponsored by an agency of the United States Government. Neither the United States Government nor any agency thersof, nor any of their employees, makes any warranty, express or implied, or assumes any legal liability or responsibility for the accuracy, completeness, or usefulness of any information, apparatus, product, or process disclosed, or represents that its use would not infringe privately owned rights. Reference herein to any specific commercial product, process, or service by trade name, trademark, manufacturer, or otherwise does not necessarily constitute or imply its endorsement, recommendation, or favoring by the United States Government or any agency thereof. The views and opinions of authors expressed herein do not necessarily state or reflect those of the United States Government or any agency thereof. 


\title{
EXPERIMENTAL STUDIES OF ACTINIDES IN MOLTEN SALTS
}

\author{
by
}

\author{
J. G. Reavis
}

\begin{abstract}
This review stresses techniques used in studies of molten salts containing multigram amounts of actinides exhibiting intense alpha activity but little or no penetrating gamma radiation. The preponderance of studies have used halides becanse oxygencontaining actinide compounds (other than oxides) are generally unstable at high temperatures. Topics discussed here include special enclosures, materials problems, preparation and purification of actinide elements and compounds, and measurements of various properties of the molten volts. Property measurements discussed are phase relationships, vapor pressure, density, viscosity, absorption spectra, electromotive force, and conductance.
\end{abstract}

\section{INTRODUCTION}

\section{A. Perspective}

The importance of the actinides to society in the next 100 years can hardly be overemphasized. The communications media have publicized widely the potential destructiveness of energy release from actinides. Less widely known is that the useful energy derivable from economically recoverable actinides (uranium and thorium) is 5 to 20 times as great as the energy derivable from all economically recoverable fossil fuels. ${ }^{1}$ This fact establishes the economic importance of developing efficient processes for preparing thorium, uranium, plutonium, and their compounds. Beyond that economic imporance, the study of the actinides is technically fascinating. The actinide series is analogous to the lanthanide series, with similarities and differences between homologs and interesting and unexplained changes in properties during progression through the respective series.

The actinides are chemically active metals, only slightly less active than the alkaline-eartin and rare-earth elements. Molten salt techniques in studies of actinide compounds often resemble those used in studies of rareearth and alkaline-earth compounds, but there are im- portant differences. The actinides are radioactive, and work with them requires special tealth protection. A particular hazard of working with plutonium and enriched uranium is that a critical mass may be assembled inadvertently.

Many of the techniques and examples discussed in this report apply equally well to work with nonactinides and have been described elsewhere, but it is hoped that there will be suificient new material in this discussion to reward the reader.

Although 15 elements (including actinium) are in the actinide series, only about 6 have been used in molten salt studies. The list of anions in molten salt studies is similarly limited. The combinations found in an extensive compilation ${ }^{2-5}$ of phase diagrams is listed in Table I as an example of the cation/anion combinations studied at high temperatures. In addition to the oxides. fluorides, and chlorides listed, 14 other phase diagrams were given for bromides, sulfates, oxychlorides, phosphates, silicates. molybdates, and tungstates of the actinides. These 14 other diagrams are included in the last column of Table $\mathrm{I}$. This distribution is typical of that of actinide-anior. combinations in other molten salt studies. Because oxides are not generally classified as salts, this report deals primarily with halides of the most abundant actinides simply because other compounds 
TABLE I. Actinide/Anion Combinations Listed in a Compilation of Phase Diagrams

\begin{tabular}{lcccc}
\hline Actinide & Oxide & Fluoride & Chloride & Total \\
\hline $\mathbf{C m}$ & 1 & 0 & 0 & 1 \\
Np & 1 & 0 & 0 & 3 \\
Pu & 4 & 3 & 9 & 16 \\
Th & 36 & 11 & 0 & 53 \\
U & 34 & 30 & 10 & 80 \\
\hline \hline
\end{tabular}

have not been studied at high temperatures, Oric reason for this lack is that the oxyanion compounds of actinides are often unstable.

\section{B. Historical Perspective}

Only four actinides (actini'ım, protactinium, thorium, and uranium) exist in nature in concentrations detectable without the most sophisticated teciniques. Actinium was discovered in 1899 by Devierne and, apparently, independently in 1902 by Geisel but was not isolated in pure form until 1947, when milligram quantities were separated from neutron-irradiated radium. ${ }^{6}$ Thorium, discovered by Berzelius in 1828, was used commercially before 1900 . Protactinium was discovered in 1918 and was first isoiated in milligram amounts in 1927. Uranium, discovered in 1789, was well known to scientists before 1900 . The remaining actinides are all synthetic and were unknown before about 1940. Plutonium was first isolated in visibic quantities as an oxide in September 1942. Neptunium, amerivium, curiurn, berkelium, and californium were isolated by 1950 . The other five actinides were discovered after 1950.

\section{Availability of Actinides}

Chemical studies (including molten salt studies) ố the actinides are limited by the restricted availability of the elements. Besides governmentally imposed regulations, there are sertain physical problems, such as limited rate of creation and isolation of the elements, coupled with short halî-lives. Only microgram quantities of transcalifornium elements will exist in the foreseeable future. Another problem is intense radiation emitted by most actinides and their daughter elements, requiring shielding and containment. Such facilities are available in oniy a few commercial and university laboraiories outside the small number of government laboratories built specifically for studies of actinides. Orderof-riagnitude values of isolated and purified supplies of the most abundant actinides and haif-lives of their most useful isotopes are listed in Table II. The actinides not listed in Table II are available only in microgram or submicrogram quantities and probably will rever be studied extensively by molten salt techniques. Studies of actinium, berkelium, and californium will be limited because of unavailability and because of their intense radioactivity. The radioactivity of americium and curium discourages their study. Protactinium is unique in that it is naturally occurring and has a long half-life but is very expensive to recover because the richest mineral source contains only a few parts per million of the element. About $125 \mathrm{~g}$ of the element was isolated from about 60 tons of ore by workers ${ }^{7}$ in the UK. This quantity is sufficient for experimentation using ordinary techniques; however, its high cost dictates conservation.

\begin{tabular}{|c|c|c|c|}
\hline TABLE & $\begin{array}{l}\text { Availability and } \mathrm{Hal} \\
\text { tinides }\end{array}$ & -Lives of the Mos & Abundant Ac. \\
\hline Element & Quantities Available & Prevalent Isotore & Half-Life, $\mathbf{Y} \mathbf{r}$ \\
\hline Ac: & milligrams & 227 & 22 \\
\hline Th & megagrams & 232 & $1.4 \times 10^{10}$ \\
\hline $\mathbf{P a}$ & grams & 231 & $3.2 \times 10^{4}$ \\
\hline $\mathbf{U}$ & megagrams & 238 & $4.5 \times 10^{9}$ \\
\hline $\mathbf{N}_{2}$ & kilograms & 237 & $2.1 \times 10^{6}$ \\
\hline $\mathbf{P u}$ & megagrams & 239 & $2.4 \times 10^{4}$ \\
\hline Am & grams" & 241 & 458 \\
\hline Cin & grams" & 244 & 18 \\
\hline $\mathbf{B k}$ & milligrams & 249 & 0.86 \\
\hline $\mathbf{C r}$ & milligrams & 249 & 360 \\
\hline
\end{tabular}

"It is planned that kilograms of compounds of americiom and curium will be isolated, but batch sizes of only $10 \mathrm{~g}$ or less are amenable to studies of molten salts without extensive radiation shielding. 


\section{SPECIAL ENCLOSURES REQUIRED FOR AC- TINIDES}

\section{A. Health and Safety Standards}

Anyone wishing to conduct experiments with actinides or actinide compounds must face governmental regulation of their possession and use. The experimenter may have to deal with the International Atomic Energy Agency, the United States Nuciear Regulatory Commission and Department of Energy, state agencies, and local government agencies. ${ }^{8-10}$ Some of the regulations limit mere possession of these elements, much less their use. The various regulatory agencies will insist that certain guidelines be obeyed before operating licenses are issued, and these guidelines will dictate radeoffs between amounts of actinides to be used and the complexity of the facility that must be constructed to hancle the material. These guidelines dictate irradiation levels allowable for various body parts of the operators; degree of environmental protection from radiological and toxic chemical release during normal operation and in case of fire, explosion, tornado, and natural disasters; and other items too numerous to mention here. Among the well-known sources of these guidelines are the International Atomic Energy Agency Safety Standards, the Scientific Committee on the Effects of Atomic Radiation of the United Nations, the (US) National Council on Radiation Protection, the International Commission on Radiation Protection, and the Advisory Committee on the Biological Effects of Ionizing Radiation of the National Academy of Sciences National Research Council. In the US, the Nuclear Regulatory Commission regulations appear in the Code of Federal Regulations, Title 10 , Chapter 1 -Energy. The regulations of other US agencies such as the Environmental Frotection Agency and the Department of Transportation also govern handling of the actinides and are listed in other titles of the code. Additional information concerning health and safety standerds and practices can be found in Refs. 8-10.

\section{B. Benchtop and Chemical Hood Enclosures}

Before about 1940 little thought was given to respirator protection of workers handling massive amounts of the then commonly available actinides, thorium and uranium. Work with these compounds was commonly performed on open benchtops without limitation. During the 1940s, general awareness of the nature of radioactivity increased as more intensely radioactive actinides became available. Consequently, government regulations were set up in an attempt to legislate safety for workers.
Selecting the enclosure to be used for an actinide project is mostly left to the experimenter and his employer. This is not to say that the experimenter has much freedom in this matter. Managers of various laboratories apparently differ widely in interpreting regulations. The nature of the enclosure required is determined in part by regulations, in part by the nature of the operation, and in part by the amount of actinide involved. Aqueous chemistry experiments involving micrograms of even very highly active members of the series are performed in chemical hoods, whereas larger quantities of the same element in powder form must be handled in an enclosure of much higher integrity. Within certain guidelines the safety of each series of experiments must be evaluated independently to determine the enclosura or hood requirements.

\section{Gloveboxes}

Gloveboxes have been used for much of the research, development, and production work with actinides. The basic enclosure may be a cube measuring about $75 \mathrm{~cm}$ on each edge, with a window and a pair of elastonier gloves about $75 \mathrm{~cm}$ long with $20-\mathrm{cm}$-diam cuffs. Blocks of this sort may be made taller, combined side by side and back to back (omitting sice or back walls from the combination as appropriate), or both to accommodate the equipment for the operaticns. An airlock or antechamber in which radioactive contamination is kept at a low level should be provided to avoid escape of radioactive material to the environment during introduction of laboratory equipment or chemicals. The enclosure must be "leak free" and must have a system to control the internal pressure at a value slightly below ambient laboratory pressure. The construction materials must be suitable for the operation and must conform with standards of resistance to fire, earthquake, pressure differential, radiation, and other problems. Early gloveboxes were constructed of plywood, ordinary window glass. and obstetrical gloves. The basic glovebox has evolved to meet the needs of various laboratories, but those facilities have retained certain design features. Unique features have evolved from stronger emphasis on different criteria at different facilities. For instance, one facility may place emphasis on fire safety, another on resistance to failure at high pressure differential, another on operator comfor, another on extreme leak tightness. anci so on.

Gloveboxes used at the Los Alamos National Laboratory will be discussed in some depth as an example. not because these gloveboxes are the best for all processes or experiments, but because they meet $c^{-}$exceed US safety criteria and are used for molten salt experiments and pyrochemical processing operations. Figures 1 and 2 


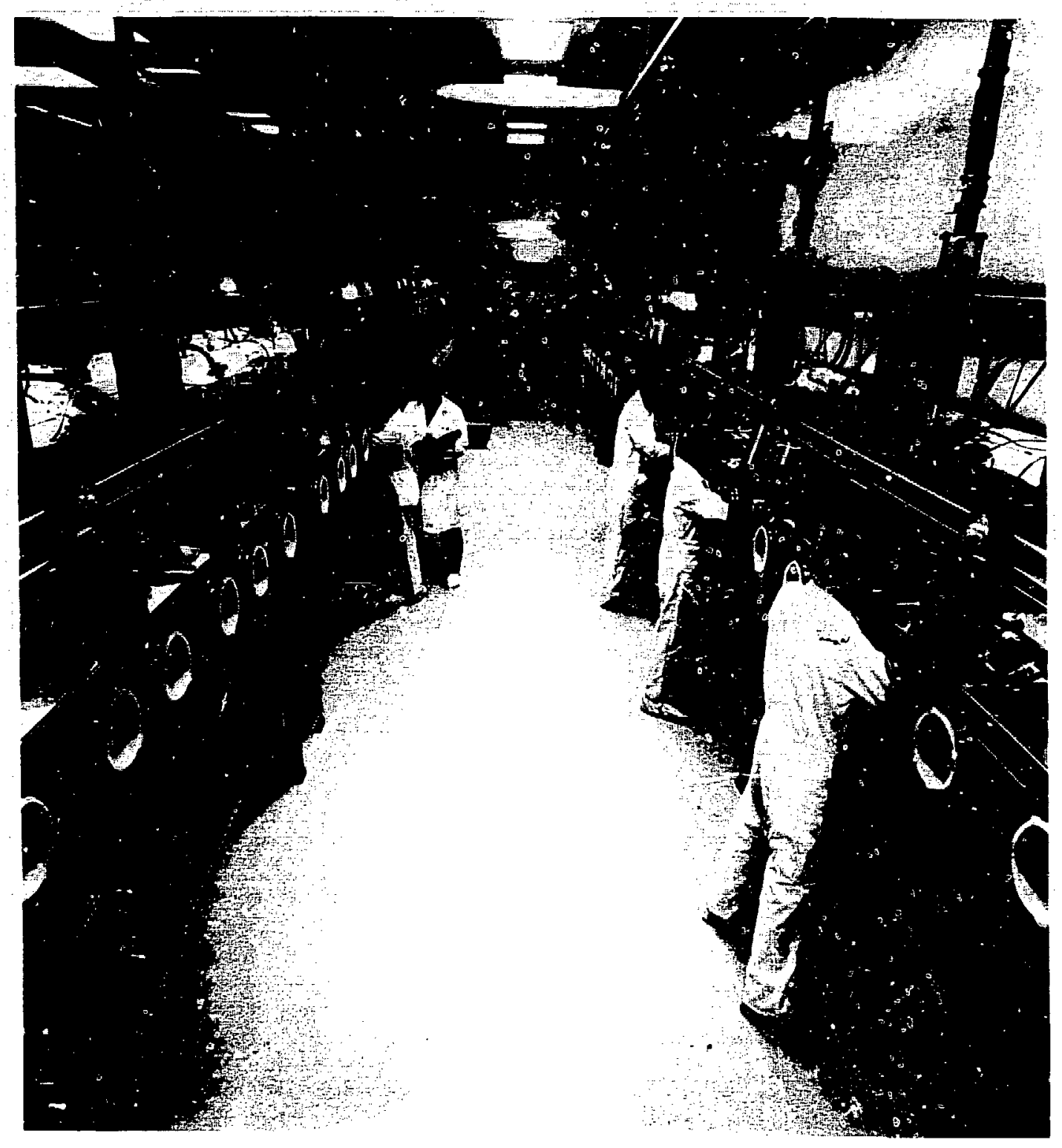

Fig- ". A tyical laboratory at the Los Alamos Plutonium Facility. 


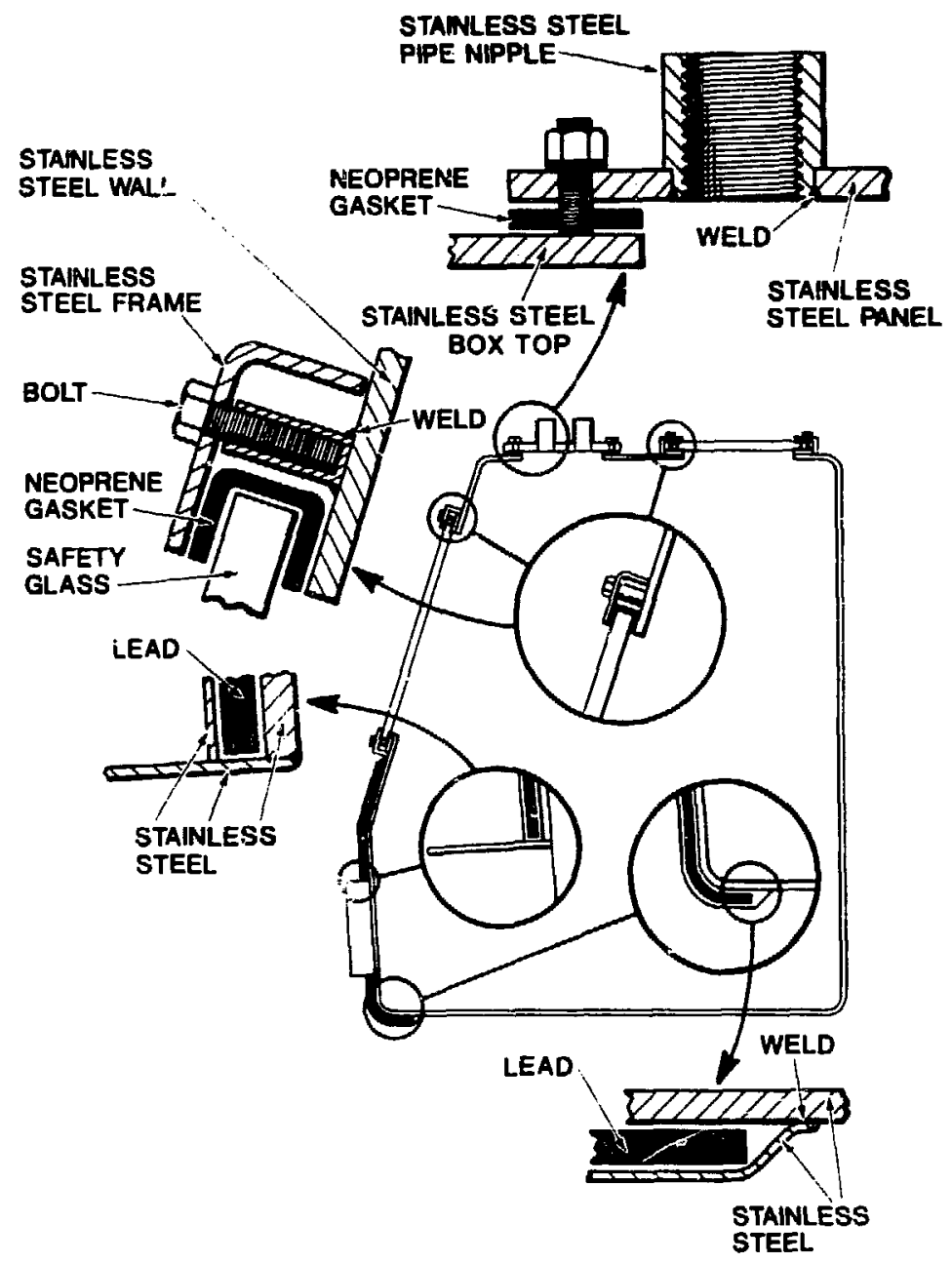

Fig. 2. Cross section of a glorebox enclosure showing some of the details of construction. The glovebox shown hare has work stations with $75-\mathrm{cm} \times 75-\mathrm{cm}$ floors and a height of $80 \mathrm{~cm}$.

show features of these enclosures. The boxes are fabricated from stainless steel Type 304 or 316 chosen for the appropriate corrosion resistance. Their welds are polished to the smoothness of the adjacent metal. Floors have a No. 4 finish; the walls and tops have a $2 \mathrm{~B}$ finish. Sharp corners are avoided. The radius of the inside comers is $25 \mathrm{~mm}$. These features aid in cleanliness, which helps in two ways to reduce the radiation background. First, because rough surfaces are difficult to clean, they accumulate thin layers of the actinides that are handled inside the enclosure. Thin films of this sort do not have the self-absorption that dense, massive samples have, so a small amount of actinide in the film contributes inordinate radiation to the general background. Second, if the actinide film remains on the wall for a long period (longer than the normal glovebox residence time for the bulk of the material), it may accumulate radioactive decay products that often have greater radiation energy than was emitted by the parent.

The standard 0.25 -in.-thick window is held in place by a neoprene gasket that requires a stainless steel frame or one that requires no frame. The stainless steel walls and floors are approximately $5 \mathrm{~mm}$ thick except for stronger floors in enclosures contairing very heavy equipment. The gloves are neoprene or a similar elastomer and are at least $0.38 \mathrm{~mm}$ thick.

The gloveboxes described above give adequate protection for handling large quantities of thorium, natural uranium, and highly enriched uranium. They are also adequate for handling up to a kilogram of plutonium containing less than approximately $1 \%{ }^{241} \mathrm{Pu}$ and having had americium separated from it within the 
previous few months. If multikilograms of plutonium are being processed or if the ${ }^{241} \mathrm{Am}$ decay product has been allowed to accumulate several months from decay of ${ }^{241} \mathrm{Pu}$ present at concentrations of about $1 \mathrm{~K}$, the additional radiation emission of ${ }^{241} \mathrm{Am}$ requires extra shielding to protect personnel. Such usage should be anticipated by including 0.25 in. of lead shielding in the walls of the enclosure during fabrication. The detail of Fig. 2 shows how the lead is covered by a thin layer of stainless steel welded to the shell of the box to make an easily cleanable outside surface. This construction eliminates exposed cracks at the edge of the lead and makes decontamination much easier when inadvertent contamination of the laboratory occurs. Adding lead glass outside the safety glass easily provides additional shielding for windows. Additional shielding for hands may be provided by lead-impregnated gloves available in thicknesses up to $1.65 \mathrm{~mm}$. When these modifications are made, the enclosure is safe for handling multigram quantities of americium, even in dilute solution where self-shielding is minimized. Multigram quantities of ${ }^{237} \mathrm{~Np}$ and ${ }^{233} \mathrm{U}$ may also be handled in such an enclosure if exposure times are kept short. However, more lead shielding must be added for routine operations with these isotopes. Plutonium-238 processing is routinely performed in the same type of enclosure with the addition of about 15-cm-thick hydrogenous shielding (either tanks of water or slabs of plastic). The hydrogenous shielding protects against neutrons produced by alpha-neutron reactions from the intense alpha particle emission of ${ }^{238} \mathrm{Pu}$.

Glovebox enclosures have been used for many pyrochemical experiments and processing operations involving molten salts. This type of enclosure is better than benchtop and open-hood enclosures when corrosive and hygroscopic materials are being used (even if they are not radioactive) because the atmosphere can be controlled to eliminate undesirable side reactions. Commercial, regenerable air dryers using dual beds of molecular sieve material can maintain air atmospheres in enclosures with water concentrations of about $1 \mathrm{ppm}$. Similarly, "boil off" gas from liquid argon or nitrogen can be used in a once-through flow system to maintain atmospheres with oxygen and water concentrations less than $10 \mathrm{ppm}$. Recirculating purifiers use dual, regenerable sorbent beds containing molecular sieves and molecular sieves loaded with activated copper or nickel to maintain atmospheres of this quality. The enclosure must be virtually leak free. Very sensitive leak detection instruments such as a commercial helium mass spectrometer leak detector must be used to ensure freedom from leaks. The allowable leak rate of enclosures operating at oxygen and water concentrations of $10 \mathrm{ppm}$ are orders-of-inagnitude smaller than the allowable leak rates for air atmosphere enclosures for intense alpha emitters such as plutonium and americium. If one de- velops even a pinhole in a glove of an inert atmosphere enclosure, instrurnentation for detecting oxygen and water leaks responds much more quickly than instrumentation for detecting escape of radioactive particles.

\section{Remote Handling}

The actinide researcher can almost always avoid the use of remotely operated hot cells if the proper isotopes are available and if the amount of actinide can be kept small and repurified often to remove highly active decay products. The small amounts of berkelium and heavier actinides that are available almost force the use of microchemical techniques for their studies, so the question of using remote operation and intermediate-shielding facilities for research is moot.

Separating transuranium elements from irradiated sources is a different matter. Transuranium actinides are commonly produced by irradiating actinides in high-flux reactors. Many intensely radioactive elements are created during irradiation, so the wanted actinides must be isolated in highly shielded hot cells. Most or all of these separations are done by aqueous procedures, but there are arguments ${ }^{15}$ that molten salt processes should be developed. The expected benefits of pyrochemical processing include freedom from radiation damage of solvents, extractants, or ion exchange resins, and production of a smaller volume of radioactive waste products, whose disposal is quite expensive. Pyrochemical processing should be considered not only for preparation of research quantities of actinides, but should also assume great commercial importance in separating fertile and fissionable fuel from spent reactor fuels.

Figure 3 illustrates the cross-section and plan views of a typical research hot cell facility ${ }^{12}$ with four cells containing individual alpha containment enclosures. These cells are separated by thick steel doors from a corridor used for transferring highly active samples from shielded shipping casks to an alpha enclosure or a storage well. These are typical cells for research with highly active gamma emitters. Cells of this size can also be used for processing kilogram quantities of irradiated fuel or isotope source material by pyrochemical methods where the reactants are kept in a very dense, compact form. Work with manipulators is extremely time consuming and maintenance of hot cells is very expensive. Hot cells are also expensive to construct and they require much space in expensive buildings that meet criteria for actinide containment. It is usually less expensive to set up equipment for microchemical measurements of chemical anci physical properties. These are possible when the pure actinides are available free from large amounts of other radinactive materials. Less time is often required for hands-0.7 microchemical 


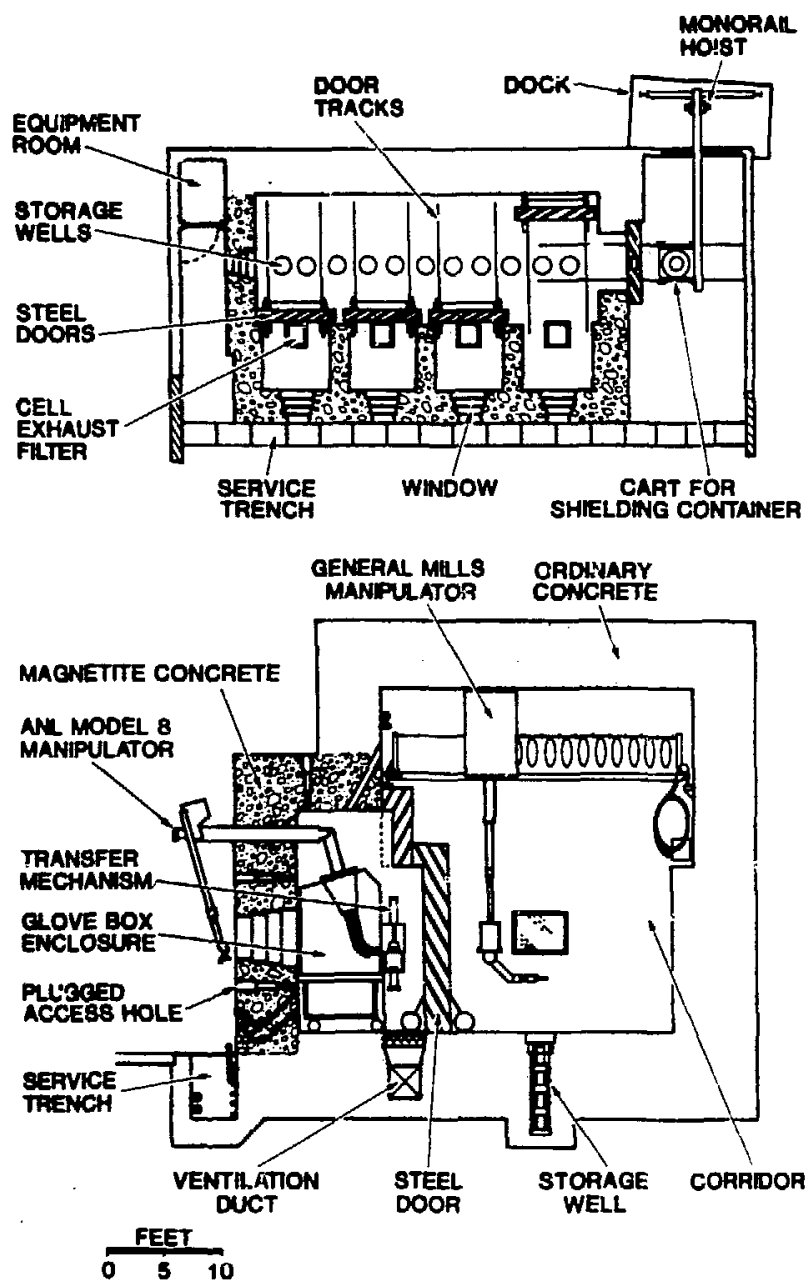

experiments than for cumbersome operations performed with manipulators. Some measurements in molten salt studies, however, are extremely difficult to make by microchemical techniques and may be done more efficiently in a hot cell. Additional information concerning design and operation of enclosures for handling the actinides and their compounds is given in Refs. 8, 10, and 13.

\section{MATERIALS PROBLEMS}

\section{A. Degradation by Radiation}

Irradiation degrading of chemicals, elastomers, and glass is severe in hot cells where irradiated materials are handled, but because reprocessing does not extensively employ molten salts or pure actinides (except as an end product), materials degradation in high-intensity
Fig. 3. Plan and cross-section views of four hot cells used for research and small-scale production operations with actinides containing intense gamma radiation emitters. gamma fields will not be discussed here. This subject is thoroughly covered in many publications, including Refs. 8, 14, and 15. Less well known is the severity of radiation damage by intense alpha emissions of some of the actinides. The intensity of alpha particle emission by protactinium, thorium, natural uranium, and the most commonly used isotope of plutonium (mass 239) is low enough to cause almost negligible effects.

Storage of the less active actinides, even in kilogram amounts, as solutions or dry compounds in polyethylene or glass containers presents no particular problems (subject to critical-mass limitations). Plutonium-238 and more active actinide isotopes, however, do cause significant container degradation. Even milligram amounts of these actinides should be stored in nonreactive metal containers. Plastics are degraded quickly, not only by the intense alpha irradiation, but also because of the heat generated locally. Glass vials containing fractional gram amounts of ${ }^{238} \mathrm{Pu}$ crack, 
probably because of large thermal gradients rather than because of radiation damage.

The isotopes having higher intensities of alpha emission significantly deteriorate most organic materials. Although it is practical to use 0.4 -mm-thick neoprene gloves or enclosures for ${ }^{239} \mathrm{Pu},{ }^{238} \mathrm{Pu}$ deteriorates these gloves rapidly and requires Hypalon-coated gloves at least $0.6 \mathrm{~mm}$ thick. Hypalon is a modified polvethylene manufactured by Du Pont. Silicone grease may be used for days to weeks on ground glass joints and stopcocks of an experimental apparatus for handling ${ }^{239} \mathrm{Fu}$, but ${ }^{238} \mathrm{Pu}$ in the same apparatus produces unacceptably rapid increases in grease viscosity. Exhaust filters on enclosures used for handling multigram quantities of powdered compounds of the more intense alpha emiters must be fabricated with radiation-resistant glues. If silicone or other types of oils are used in pressure-relief devices on such enclosures, they must be checked periodically to ascertain that the oil has not become so viscous that the device malfunctions. These effects are seen even in enclosures with inert atmospheres. If the enclosure atmosphere is air containing water vapor at ambient relative humidities, these effects are accelerated and corrosion of metals and corrosion-resistant materials becomes serious. There is speculation that ozone formed in air subjected to alpha radiation may be important in accelerating corrosion. Some workers have attempted to remove ozone from enclosure atmospheres by decomposition on $\mathrm{MnO}_{2}$ to reduce the rate of corrosion. The lighter, halogenated hydrocarbons (such as freons) are similarly degraded and produce corrosive products.

As was mentioned, one way to keep radiation damage (either to personnel or to equipment and enclosures) to a minimum is to keep actinides and their compounds confined to the minimum volume (within thermal and criticality constraints) to provide seif-shielding. Avoiding thin deposits of alpha emitters on elastomers such as glovebox gloves is very important. Good housekeeping can hardly be overemphasized.

\section{B. Container Compatibility at High Temperatures}

Problems of containing molten actinide salts are very similar to problems of containing salts of other active metals such as the alkali, alkaline-earth, and rare-earth elements. The radioactivity of the actinides adds little to the experimental problems, other than the general problems of handling radioactive substances. Much information about container compatibility has been generated, however, in research on actinide salts, in particular metal/salt systems and fluoride systems. The latter have been studied extensively in the Molten Salt Reactor Experiment program. ${ }^{16.17}$
Two types of containment problems are encountered in molten salt work. One is reaction of the container with the contents, which contaminates the contents to make the reaction product undesirable, or changes the property being measured in an experiment, or both. The second type of problem is seepage of the liquid into pores or through cracks in the container, not significantly contaminating the contents. The latter problem is often more significant in work with actinides (compared with nonactinides) because of their value and because the actinide must be recovered from th $\approx$ container after the operation. The effort to recover the actinide often is much greater than the effort to observe or prepare a compound. Because absolute recovery of the actinides is impossible, the scrap from the original container and wastes generated during recovery will all have low-level contamination and must be disposed of by elaborate and very expensive methods.

Misadventures involving container breakage and release of actinides may have grave consequences. If a salt or salt/metal mixture at high temperatures is released not only from its primary container but also from the glovebox enclosure, reaction with the atmosphere may lead to dispersal of finely divided radioactive material. This may be inhaled by personnel or may contaminate the building severely. If batches of hundreds of grams of anhydrous fissile material are being handled, they must be kept from mixing with water or other hydrogeneous material, which event could lead to criticality.

These constraints necessitate choices of materials and designs often more expensive and conservative than would be used for containment of nonradioactive materials. Double containment is often specified for actinides where single containment would be used for other elements. Limited-volume, recirculating cooling water systems prevent flooding of enclosures and possible criticality incidents. High.density vitrified ceramic crucibles minimize loss of accountable material to crucible scrap. These elements require additional design time and safety analyses.

Chemical reactions with container materials must be carefully considered before starting work with molten salt systems containing actinides. Experiments with pure molten chloride systems may be performed in borosilicate (Pyrex) glass at temperatures up to about $500^{\circ} \mathrm{C}$, but fused quartz or Vycor $\left(96 \% \mathrm{SiO}_{2}\right)$ affords additional resistance to breakage caused by thermal shock or to melting if temperature control malfunctions. Quartz may be attacked significantly if air and water are not rigorously excluded from the system, but these should be excluded anyway to prevent direct reaction with the actinide halides to form oxides and oxyhalides. All salts put into the system must be rigorously treated by well-known methods to eliminate water and oxyhalides. Much less work has been done with actinide 
bromides and iodides and they may be expected to be thermally less stable than the chlorides, but quartz is not expected to contribute significantly to their decomposition. Fluorides, on the other hand, are expected to react with siliceous materials at elevated temperatures, although a report ${ }^{18}$ on spectra of actinides in mixed fluoride/chloride molten salts did not mention reaction with quartz cells. Platinum and gold have been used as containers for experiments with fluorides, and extensive corrosion studies of fluoride systems containing thorium and uranium fluorides were carried out in the Molten Salt Reactor Experirnent program. ${ }^{16,17}$ The best containment for flowing molten fluoride salts in large systems was provided by Hastelloy $\mathrm{N}(7.4 \% \mathrm{Cr}, 4.5 \% \mathrm{Fe}$, $17.2 \% \mathrm{Mo}$, and $70 \% \mathrm{Ni}$ ) and by titanium-modified Hastelloy $\mathrm{N}(7.3 \% \mathrm{Cr}, 13.6 \% \mathrm{Mo}, 77 \% \mathrm{Ni}$, balance $\mathrm{Ti}) .^{19}$

Molten soit studies of actinides in oxyanion systems have been much less extensive than in halide systems. Pyrex optical cells showed no evidence of reaction with $\mathrm{LiNO}_{3}-\mathrm{KNO}_{3}$ solutions of several of the actinide nitrates at temperatures up to $250^{\circ} \mathrm{C}$. Molybdates, tungstates, phosphates, and silicates have been studied in platinum and gold containers.

The choices of containers for work with metal/molten salt systems are much more difficult than the choices for pure salts. The actinide metals react with many ordinary ceramic materials. Table III lists the approximate free energies of formation (at a common observation temperature) of selected oxides used as containers for actinide metal/salt mixtures. The free energies of formation of oxides that may form from the metals being studied are also included. Examination of the values listed in Table III leads one to choose as containers the oxides of calcium, thorium, lanthanum, cerium, beryllium, yttrium, magnesium, and aluminum, in that order. One must also consider other chemical, histori$\mathrm{cal}$, and economic factors governing the availability of containers made from these materials. Calcium oxide reacts too readily with water, thoria is radioactive, the rare earths are expensive, and beryllium presents health hazards. Thorium and the rare earths are difficult to separate from the actinides in waste recovery operations. Beryllium produces neutron radiation problems created the of the alpha-neutron reaction that curs when this element is in intimate contact with the intense alpha emitters. On the other hand, magnesia and alumina are commonly available, present no appreciable health hazards, and have been studied for many years, so fabrication techniques for these ceramics are well known. Also, magnesium and aluminum are easily separated from the actinides by traditional waste recovery techniques. For these and other reasons, something other than the thermodynamically "best" container material is often chosen for molten actinide metal/salt mixtures.

The physical properties as well as chemical properties must be considered in the selection of fabricated containers. If the time of contact with liquid phases is short and the container will be subject to thermal shock, the sintered density should be low to avoid breakage during rapid thermal cycling. If the heating cycle is slow and the liquid contact time is long, the container should be vitrified (sintered to a density approaching $100 \%$ of the theoretical density). This vitrification minimizes the surface area available for reaction and minimizes penetration of the wall by the liquid phase, which contains accountable actinides. Regardless of the density requirements of the container, undesirable reactions can be minimized by reducing roughness (and therefore reactant area) of the container's interior.

Specifications for typical magnesia containers used for routine plutonium metal preparation by molten salt reductions (see Secs. VI-B and VI-C for process descriptions) are listed in Table IV. Only recognized significant properties are specified because obviously not all properties can be. One manufacturer's product might meet these specifications and be satisfactory, but another manufacturer's product made to the same specifications might be unsatisfactory because an unknown, unspecified property may be critical to the success of the process. This factor might contribute to contradictory reports fromi different laboratories about the suitability

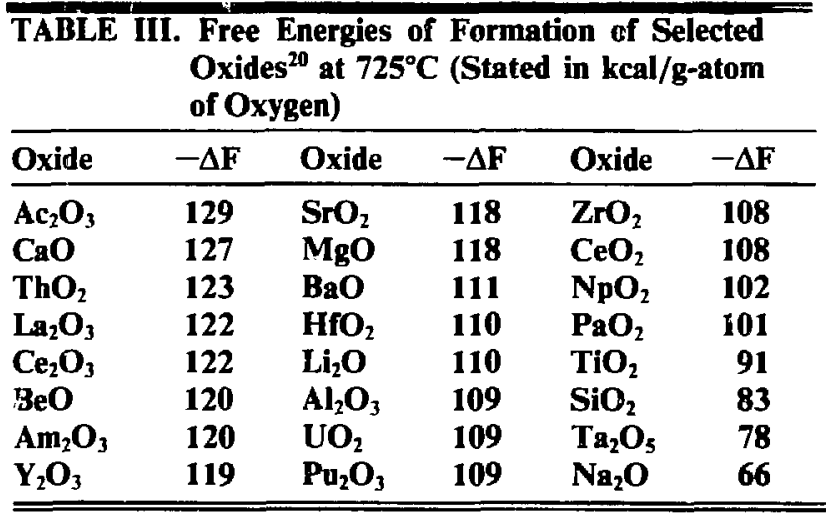




\begin{tabular}{|c|c|c|}
\hline \multicolumn{3}{|c|}{$\begin{array}{l}\text { TABLE IV. Partial List of Specifications for Magnesia Crucibles } \\
\text { Used for Plutorium Metal Preparation At Los Alamos } \\
\text { by Bomb Reduction of the Fluoride and Direct } \mathrm{PuO}_{2} \\
\text { Reduction in } \mathrm{CaCl}_{2}\end{array}$} \\
\hline $\begin{array}{l}\text { Items } \\
\text { Specified }\end{array}$ & Bomb Reduction & Direct Oxide Reduction \\
\hline $\begin{array}{l}\mathrm{MgO}^{\circ} \\
\mathrm{CaO} \\
\mathrm{SiO}_{2} \\
\mathrm{SiO}_{2} / \mathrm{CaO} \text { wt. ratio } \\
\mathrm{Fe}_{2} \mathrm{O}_{3} \\
\mathrm{Al}_{2} \mathrm{O}_{3} \\
\mathrm{Be} \\
\mathrm{Pb}, \mathrm{Ca} \\
\mathrm{Ti} \\
\mathrm{Ga}, \mathrm{C} \\
\mathrm{B}, \mathrm{Mn}, \mathrm{Ni}, \mathrm{Zr}, \mathrm{Cr}\end{array}$ & 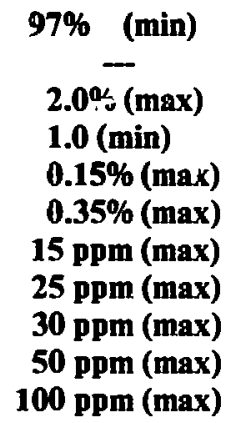 & $\begin{array}{r}98.5 \% \text { (min) } \\
1.0 \% \text { (max) } \\
0.5 \% \text { (max) } \\
- \\
0.15 \% \text { (max) } \\
0.35 \% \text { (max) } \\
15 \text { ppm (max) } \\
25 \text { ppm (max) } \\
30 \text { ppm (max) } \\
50 \text { ppm (max) } \\
100 \text { ppm (max) }\end{array}$ \\
\hline Porosity & $\ldots$ & $\begin{array}{l}\text { No Open porosity; } \\
\text { no penetration by } \\
\text { ethanol when crucible } \\
\text { is filled. }\end{array}$ \\
\hline Density & $\begin{array}{l}2.8 \mathrm{~g} / \mathrm{cm}^{3} \\
(78 \% \mathrm{TD})\end{array}$ & Vitrified inside surface. \\
\hline Cracks & - & $\begin{array}{l}\text { None detectable by dye } \\
\text { test. }\end{array}$ \\
\hline
\end{tabular}

of containers. For instance, Los Alamos National Laboratory experience shows that magnesia crucibles perform better than alumina crucibles in preparation of plutonium, ${ }^{21}$ whereas experiments at the A.tomic Weapons Research Establishment found the opposite. ${ }^{22}$ With the state of the art, one may select a container material for molten salt/metal systems based on thermodynamic and special chemical considerations, write specifications of physical properties expected to best fit the use, try samples from several fabricaters, and finally select the one that gives the best performance.

Refractory metal containers should not be overlooked as containers for molten actinide salt/metal mixtures. The ones most often used have been tantalum, tungsten, molybdenum, and alloys of these elements. The solubility of these elements in molten actinide metal is low, and freedom from anion contamination, often contributed by ceramics, is a significant advantage of metal containers. The most serious problem with these containers is removal of the metal phase from the container after the experimental measurement or reaction. Sometimes surface treatments such as oxidation of tantalum crucible surfaces prevent wetting of the container by the pure actinide metals, but molten salts often break down such interfaces, so the actinide metal wets the crucible and cannot be removed after solidification except by aqueous dissolution, an undesirable procedure. A long-term goal for actinide pyroprocessing is transfer of moiten salt and metal products from metal reaction containers as liquids, ${ }^{23}$ but success of efforts to achieve this goal has been limited.

\section{MICROTECHNIQUES}

For this discussion, the term "microtechnique" will be expanded to include techniques for handling microgram to milligram quantities of the element being studied because an apparatus beilt to study microgram samples can often be easily mc ified for study of milligram quantities. Microtechniques are well suited to studies of the actinides. Except for thorium, uranium, neptunium, plutonium, americium, and curium, world supplies of actinides are very small, and a laboratory may not be able to procure even milligram amounts. Except for natural thorium and uranium, the actinides are all very expensive. Health, safety, and security regulations may allow work with milligram quantities of some of the elements in a specific laboratory, but possession of gram or multigram quantities in that laboratory may be forbidden. Even if available quantities of actinides were not limited by these external 
factors, there are other reasons for minimizing their quantity. The intense radioactivity of many of the actinides creates problems of personnel irradiation, equipment degradation, and generation of heat that can cause difficulties in control of the sample temperatire.

Despite many reasons for using microtechnigues in molten salt studies of the actinides, their application has been limited. This is probably because such work (particularly with the most highly radioactive and least available elements) is very expensive in terms of money and time, and the rewards are limited to extending knowledge with few perceived industrial applications. Microtechniques using molten salts have been applied almost exclusively in preparative chemistry and almost not at all in studying properties of the moiten salts themseives.

Study of actinide compounds by microtechniques began in about 1942 because only microgralil quantities of the synthetic elements were available. One of the pioneers was B. B. Cunningham, whose 1961 article $^{24}$ is a valuable reference, as are later reviews. ${ }^{25.26}$ The earliest work was a study of both aqueous and dry chemistry of plutonium and its compounas. Since then, transplutonium metals up to and including californium liave been prepared by microtechniques. Two generalized reactions have been employed to prepare these metals:

$A n F+M_{(g)} \rightarrow A n+M F$

and

$\mathrm{AnO}+\mathrm{M}^{\prime} \rightarrow \mathrm{An}_{(\mathrm{g})}+\mathrm{M}^{\prime} \mathrm{O}$

where $A n$ is an actinide, $\mathbf{M}$ is a volatile active metal (generally lithium or barium), and $\mathbf{M}^{\prime}$ is a nonvolatile metal (generally lanthanum or thorium). Figure 4 shows a furnace for reducing actinide compounds to metals. When lithium is the reductant, it vaporizes at the temperature of reduction and reacts as a gas with the (molten) fluoride supported by the wire spiral (or cup), producing volatile lithium fluoride and a bead of actinide metal that sticks to the wire spiral or cup. The lithium fluoride emerges as a gas from the hole in the top of the crucible lid. The operator removes the cooled metal from its support by peeling away the refractory wire or foil. When barium is the gas-phase reductant, the siag (barium fluoride) is chipped away from the metal.

When a nonvolatile reductant (lanthanum or thorium metal) is used to reduce oxides, the actinide oxide and the reductant are mixed in the bottom of the crucible, the susceptor shown by Fig. 4 is omitted, and the volatile actinide metal product vaporizes and is collected on a target suspended above the effusion hole in the cruciole lid.

Figure 4 can be considered to represent a general apparatus for preparing and reducing actinide salts. The

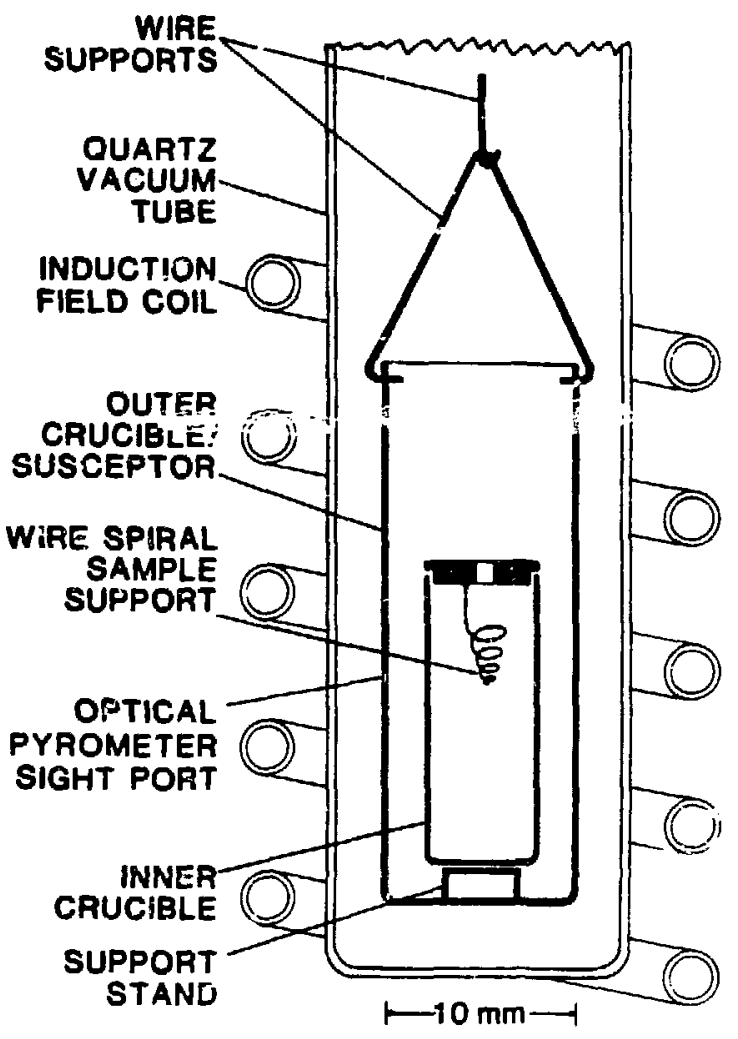

Fig. 4. Cross section of a typical induction-heated double-wall microfurnace.

actinide often emerges from aqueous purification $a b-$ sorbed on ion exchange beads. These beads can be calcined in the same type of furnace, except that the construction material must be platinum. Treatment with $\mathrm{HF}-\mathrm{H}_{2}$ converts the resulting oxide to fluoride in a similar monel furnace. Other halides may be prepared similarly with other hydrogen halides. Such experiments with small samples must be carefully planned to minimize sample transfers, thus avoiding a lost or contaminated sample. Unfortunately, transfers may be required because few container materials are suitable for both reducing and oxidizing conditions at high temperatures.

Physical properties of molten salts that may be measured in very small samples include vapor pressures, melting püints, and absorption spectra. Measuring these properties by conventional techniques will be discussed later in this report, but app'ying microtechniques to melting-point and absorption spectra measurements will be discussed here. The operator can easily estimate melting points of high-melting (above $750^{\circ} \mathrm{C}$ ), high-purity, irregularly shaped salt crystals as small as $1 \mathrm{~mm}^{3}$ if he simultaneously views slumping 
during heating and measures the sample's temperature by using a hot-wire telemicroscope optical pyrometer. This technique has two major faults. The first is that the crystal and its background must be at different temperatures to provide contrast making the crystal visible, thereby violating a primary rule of optica! pyrometry that exact temperatures can be measured only under blackbody conditions. The other problem is encountered with relatively volatile compounds, which appear to slump when the sharp corners are sublimed. Nevertheless, reasonably accurate (often within a few degrees) determinations of melting point may be made simply with a properly designed oven and a good telemicroscope pyrometer. Another method of melting point determination that has been used on microsamples of metals is observation of the temperature at the instant of collapse of a bead compressed between the arms of a tungsten wire slip. ${ }^{27}$ This technique should work equally well for determining melting points of pure salts.

Absorption spactra of molten salts may also be measured by microtechniques..$^{28,29}$ Light from a source is focused by a microscope objective lens on the sample in a quartz capillary or other suitable microsample holder. The transmitted light then passes through another microscope objective or condensing lens and is focused on the aperture of a monochromator, which transmits the spectrum to a suitable detector. Systems of this type have been built from components on opticai benches or have been used in the sample compartments of commercial spectrophotometers. In the only report of molten salt observation, the sample was in a quartz. capillary heated by a coil of platinum wire. ${ }^{29}$ Converting other types of sample holders, such as thin metal sample holders on which tine sample is mounted in a pinhole of an electricaliy heated sample holder, should be relatively easy. Recently introduced spectrophotometers ${ }^{30}$ that use fiber optics to direct the analyzing light beam might further simplify measurement of absorption spectra because the analyzing beam can be conducted through a furnace in any position in an enclosure while the light supply, dispersion, and detecting systems remain outside.

Although microtechniques have some advantages over larger-scale work, they also have some drawbacks. Microsamples nust be kept scrupulously clean. Unseen bits of impurities added to microsamples may produce mixtures with significant mole fractions of unwanted elements in the sampie. Although corrosion oi a sample support may not be visible, even with optical aids, microscopic corrosion may have introduced significant impurities. Microsamples are so small as to defy accurate analyses after the preparation or experimental measurement so that one can seldom prove that the material used was really pure.
Another problem with microchemical work at high temperatures is accurate measurement of temperatures. When the double-container technique is used (Fig. 4). it is easy to measure temperatures accurately with the optical pyrometer, but if the sample is suspended in an unshielded position, unknown emissivity corrections cause significant uncertainties in values of sample temperatures. When thermocouples are used to measure temperatures of unshielded samples, it may be impossible to attach the thermocouple junction to the apparatus in sufficient proximity to the sample to measure temperature accurately. This is because temperalure gradients are often high in small furnaces with minimal radiation reflection, so heat conduction from the junction by the thermocouple leads may cause sig nificant errors.

Despite these limitations, many measurements are surprisingly accurate. For instance, it was repurted ${ }^{27}$ in 1951 that the melting point of neptunium metal determined by observing two samples weighing $200 \mu \mathrm{g}$ each was $640 \pm 1^{\circ} \mathrm{C}$. Later multigram measurements indicated a melting point of $637^{\circ} \mathrm{C}$. On the other hand, the melting point of two samples of americium metal weighing about $1 \mathrm{mg}$ eachi was observed ${ }^{31}$ to be $994 \pm$ $7^{\circ} \mathrm{C}$. Later determinations of the melting point using multigram samples ${ }^{32}$ indicate the correct meluıg point is $1175 \pm 3^{\circ} \mathrm{C}$. These examples illustrate that microtechniques can be very useful and can produce accurate data but that extra calition may be required in their use.

\section{TECHNIQUES FOR FURIFYING IMULTI- GRAM QUANTITIES OF ACTINIDES AND THEIR SALTS}

The actinides used on the scale familiar to most chemists in universities and indusiry are thorium, uranium, and plutonium. Intermediate quantities of protactinium and neptunium are available, and smaller amounts of americium and curium are used, not necessarily because the supply is small, but because of their intense radioactivity. These seven elements are discussed in this section; the remaining actinides are best studied by the microtechriques of Sec. IV.

\section{A. Aqueous Methods}

The traditional aqueous separation and purification methods of ion exchange, solvent extruction, and precipitation are used to separate actinides from anionic and cationic impurities. As was pointed out in the discussinn of microtechniques, the product of microchemical-scale purification of actinides was often one or 
a few ion exchange beads loaded with the desired element. Aqueous actinide preparation and purification on the multigram scale have as their predominating end product an oxide or a compound readily converted to an oxide by calcination. Compounds for molten salt work are then prepared by pyrochemical techniques. Among the limited exceptions are nitrates and some fluorioies. Very brief discussions of aqueous purification techniques are presented here.

1. Thorium. Thorium content in the earth's crust is about $10 \mathrm{ppm}$. The most important commercial source is a rare-earth phosphate mineral called monazite. Two processes have been used to recover and purify thorium on the scale of tons per year. ${ }^{33,34} \mathrm{Cne}$ ronsists of digestion in $\mathrm{H}_{2} \mathrm{SO}_{4}$, dissolution with $\mathrm{H}_{2} \mathrm{O}$, selective precipitation by $\mathrm{NH}_{4} \mathrm{OH}$, dissolution in acid, purification by solvent extraction, and precipitation as a hydroxide. The second involves digestion in $\mathrm{NaOH}$, dissolution by $\mathrm{HCl}$, and selective hydroxide precipitation. Additional solvent extraction may be required for complete separation of thorium from uranium and rare earths. The final product from aqueous processing is usually thorium nitrate tetrahydrate, thorium hydroxide, or thcrium oxalate depending on the intended use. Thorium tetrafluoride suiabi: for molten salt operations has been prepared by precipitation from aqueous solution, drying, and heating to $400^{\circ} \mathrm{C}$ in an $\mathrm{HF}$ atmosphere. Care is required to prevent doz.ble salt formation during precipitation of the fluoride is potassium or ammonium ions ire present.

2. Protactinium. Protactirium-2?1 occurs naturally as a member of the actinium series that has ${ }^{235} \mathrm{U}$ as the parent isotope. Because the half-life of ${ }^{231} \mathrm{~Pa}$ is shorter than that of ${ }^{235} \mathrm{U}$ by $a$ factor of $2 \times 10^{4}$, the equilibrium concentration of this element in uranium ores is extremely smali. Nevertheless, in 1961 workers in the UK recovered over $100 \mathrm{~g}$ of protactinium compounds from about 60 tons of uranium-processing sludge. ${ }^{7}$ After much research and development, the sequential recovery steps finally adopted were

- leaching the sludge with $\mathrm{HNO}_{3}-\mathrm{HF}$,

- separating uranium by solvent extraction,

- coprecipitating by adding $\mathrm{AlCl}_{3}$,

- removing aluminum by dissolution with $\mathrm{NaOH}$,

- dissolving the remaining solid in $\mathrm{HCl}$, and

- recovering the protactinium by solvent extraction.

The aqueous chemistry of protactinium appears complex, ${ }^{35-37}$ with hydrolysis playing a major role. The chemical behavior seems more similar to that of niobium and tantalum than to protactinium's actinide neighbors thorium and uranium. Protactinium assumes valences of 4 anc 5 in various complex compounds with other metals and nonmetai 5 . Precipitation as the iodate, which can be thermally decomposed to $\mathrm{Pa}_{2} \mathrm{O}_{5}$, appears to be the best way to begin preparing compounds for molten salt studies.

3. Uranium. The uranium content in the earth's crist is about $3 \mathrm{ppm}$. Many minerals contain economically recoverable uranium; thertiore, there are many varied extraction processes. ${ }^{38-40}$ The crushed mineral may be leached withic sulfuric acid and purified by ion exchange or solvent extraction, followed by precipitation as a peroxide or diuranate. Other processes involve leaching the ore with sodium carbonate solution. Products of these processes are usually uranyl nitrate hexahydrate, ammonium diuranate, or oxide. Uranium dioxide, which may be formed by heating the higher oxides under flowing hydrogen, is often the feed material for preparing uranium compounds for molten salt work.

4. Neptunium. Neptunium is a synthetic element prepared in nuclear reactors by the $n, 2 n$ reaction with ${ }^{238} \mathrm{U}$, forming ${ }^{237} \mathrm{U}$, which decays by beta emission to ${ }^{237} \mathrm{~Np}$ (Fig. 5). Because almost all reactors contain ${ }^{238} \mathrm{U}$, many kilograms of neptunium have been created in reactors all around the world. Another source is alpha decay of ${ }^{241} \mathrm{Am}$. The major use of neptunium is irradiation in reactors to make ${ }^{238} \mathrm{Pu}$ for heat sources. The effort expended to recover neptunium during processing of irradiated reactor tuels depends on the perceived demand for ${ }^{236} \mathrm{Pu}$. Parametirs of the solvent-extraction and ion-exchange processes normally used in processing irradiated fuels can be changed is divert neptunium to the wasie stream or to the uranium stream, where the neptunium is separated $5 . d$ recovered. The product of separaticn and purification is a solution from which neptunium(IV) oxalate is usually precipitated. ${ }^{41}$ This oxalate is calcined at about $500^{\circ} \mathrm{C}$ for target fabrication in the generation of ${ }^{238} \mathrm{Pu}$ or for neptunium metal or compsund preparation.

5. Plutonium. Plutonium-239, the most commonly encountered isotope of plutonium, is a synthetic isotope formed in reactors by neutron capture by ${ }^{238} U$ to form ${ }^{239} \mathrm{U}$. As shown in Fig. 5, plutonium formed by neutron absorption will always consist of a mixture of isotopes whose composition depends on the time and flux of irradiation. Plutonium-239 is the most desirable is tope (with the exception of ${ }^{244} \mathrm{Pu}$, whose formation in macro amounts is impractical) for chemical studies because it has a long half-life and decays by alpha emission to ${ }^{235} \mathrm{U}$, a virtually innocuous daughter element. because ${ }^{239} \mathrm{Pu}$ is the first long-lived isotope formed during neutron irradiation of ${ }^{238} U$, plutonium formed by short-term irradiations of uranium is the most desirable.

Many pyrochemical schemes have been proposed for processing irradiated reactor fuels, but almost all reprocessing is $b$ sed on solvent extraction and ion exchange. 


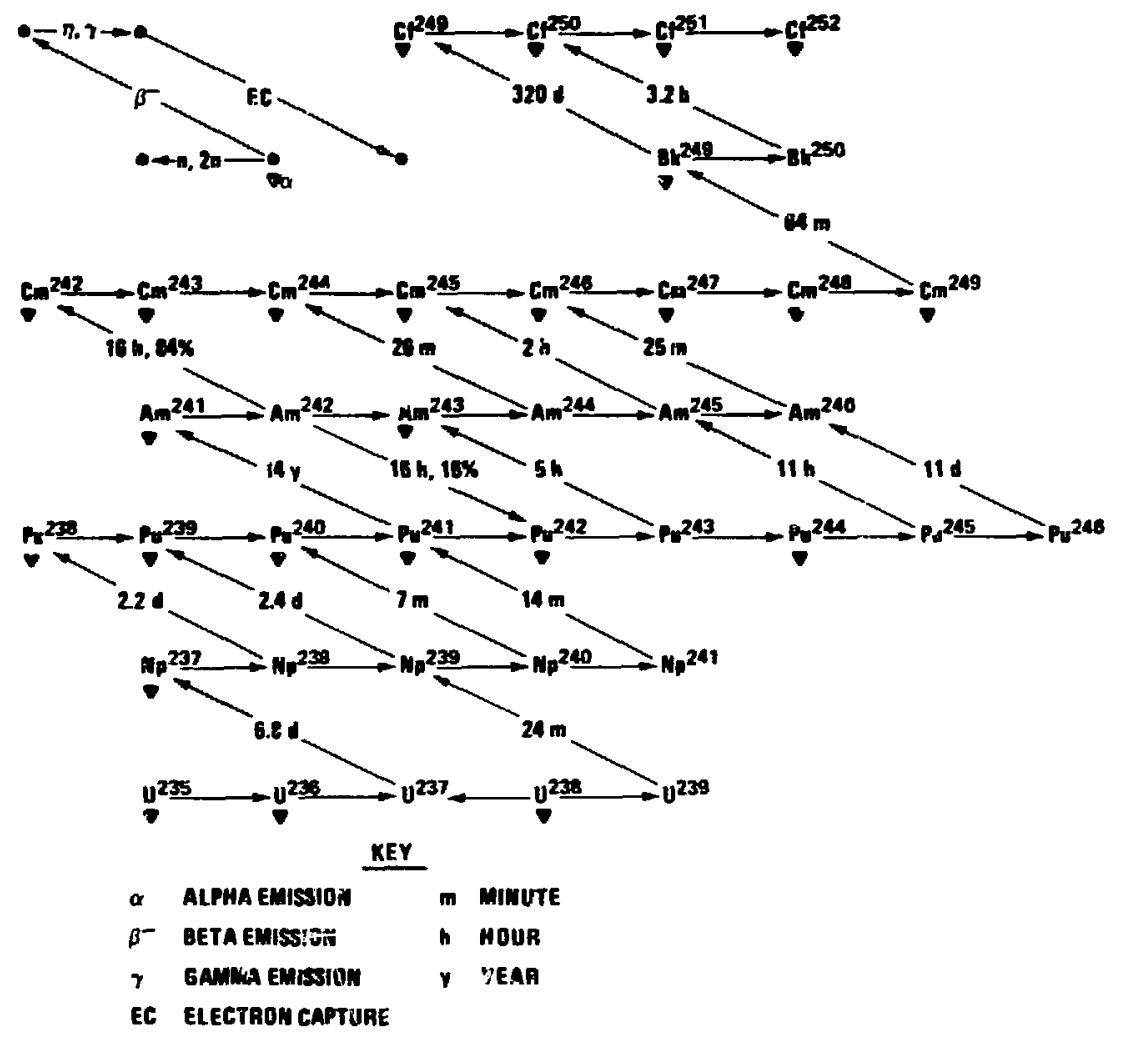

Fig. 5. Modes of formation and decay of some of the transuranium elements.

Uranium and plutosium ure first separated from fission products (which go to a waste stream) and are finally separated from each other. The plutonium usually emerges from separating and purification in nitric acid solution in the tetravalent state, although some processes deliver the product in the trivalent state. The tetravalent plutonium may be precipitated, dried, and calcined to $\mathrm{PuO}_{2}$ for further processing. Another commun treatment of the product solution is reduction of the plutonium to the trivalent state and precipitation of the o:-alate, which may be calcined to form reactive $\mathrm{PuO}_{2}$. The only common treatment of solutions for direct conversion to a sait useful in molten salt work is reduction of the plutonium to the trivalent state, followed by precipitation of the trifluoride, which may be dried by being carefully heated under flowing argon or helium to $6,0^{\circ} \mathrm{C}$. Direct precipitation of the tetravalent oxalate or fluoride is almost never done because of filtration problems with these compounds if precipitation conditions are not closely controlled. The oxide formed on calcination of the peroxide and oxalate is reactive and can be used in most preparative work, unlike the nonreactive refractory oxide formed by oxidation of the metal or by heating reactive oxide to temperatures above $1000^{\circ} \mathrm{C}$ for extended periods.
6. Americium. Americium is being created at the race of hundreds of kilograms per year, but its rate of separation and purification is considerably lower because of lack of demand. Figure 5 shows that several isotopes of americium will be created in power reactors, but careful consideration of neutron cross sections, halflives, and decay modes reveals that the most abundant americium isotopes in spent fuel for reprocessing are ${ }^{241} \mathrm{Am}$ and ${ }^{243} \mathrm{Am}$. Only a small fraction of the americium created in this way is separated and purified because very little power reactor fuel is being processed, and much of the americium in that is diverted into waste streams. Plans have been made to separate kilogram amounts of americium fronı a was: $z$ by combined solvent extraction, oxalate precipitation, and ior exchange. ${ }^{42}$ The practicality of this process will depend on the demand for americium and on perceived advantages of separating long-lived ${ }^{243} \mathrm{Am}$ from high-level wastes before disposal.

Plutonium from spent reactor fuel contains about $1 \%$ ${ }^{241} \mathrm{Pu}$, which desays by beta emission (Fig. 5) to ${ }^{241} \mathrm{Am}$. During plutonium recycling, this americium is separated and either purified or discarded to waste. Several laboratories ${ }^{43-45}$ are separating and purifying ${ }^{24 !} \mathrm{Am}$ from 
this source in multigram to kilogram quantities annually. The aqueous methods vary somewhat from laboratory to laboratory, depending on previous experience, the availability of equipment, and the composition of the americium source. The separation and purification schemes use combinations of solvent extraction, anion exchange, cation exchange, peroxide precipitation, and oxalate precipitation. In all aqueous schemes the final step is precipitation of the oxalate, which is calcined to $\mathrm{AmO}_{2}$. This oxide is the feed material for preparation of compounds used in molten salt studies. One py ichemical process $^{46.47}$ will be discussed in a later section.

7. Cium. Aqueous preparation of curium generally involves separation from americium because the two common uses of curium use a combination of the two elements. A popular method ${ }^{48}$ of preparing medicalgrade ${ }^{258} \mathrm{Pu}$ is neutron irradiation of ${ }^{241} \mathrm{Am}$ to form ${ }^{242} \mathrm{Am}$, which undergo-s beta decay to ${ }^{242} \mathrm{Cm}$, which in turn forms pure ${ }^{238} \mathrm{Pu}$ by alpha decay. Another use ${ }^{49}$ of curium is in mixed targets of ${ }^{243} \mathrm{Am} /{ }^{244} \mathrm{Cm}$, which are irradiated for the production of ${ }^{252} \mathrm{Cf}$ neutron sources widely used in industry. Curium is also found in highlevel wastes from reactor fuel reprocessing. Curium is closely associated with americium in these systems. The chemistry of the two is very similar, and curium follows americium through the processing outlined in Sec. V.A.6. Mixtures of the two are separated ${ }^{50}$ by oxidation of americium to the pentavalent state with ozone or similar oxidant so that it can be precipitated as $\mathrm{K}_{5} \mathrm{AmO}_{2}\left(\mathrm{CO}_{3}\right)_{3}$, while the curium remains in solution in the trivalent state. Curium is finally precipitated as the oxalate and calcined to the oxiue. The oxide is used as the starting point for preparing curium salts.

8. Other Actiuides. The transcurium elements are processed by highly specialized techniques involving solvent extraction and ion exchange in a hot-cell facility. ${ }^{51}$ The products are isolated in milligram or smaller amounts in special forms.

\section{B. Pyrochemical Preparative Chemistry}

For this discussion, oxides are not considered salts and will be referred to only incidentally. As inentioned previously, most of the actinide compounds of interest in molten salt chemistry are halides and, as discussed in the preceding section, reactive oxides are the prevalent product of aqueous actinide separation and purification procedures. It will be seen in this section that preparation of most anhydrous actinide salts used in molten salt work starts with a reactive oxide or an oxalate that decomposes to $c$ xide during early stages of heating.
1. Halide Preparation. Over $90 \%$ of the physical properties studies of actinide salts involve halides. The predominant method for preparing these halides is treatment of oxides (or oxalates or hydroxides that decompose to oxides during the early stages of heating) with halogens or hydrohalogens at elevated temperatures (Table $\mathrm{V}$ ). Other useful methods of preparing halides shown in Table $Y$ include converting one halide composition to another (either different valence states of a given halide or from one halide to another). Other preparations start with the actinide as metal or hydride.

Except for the compounds of ariinium and curium, most of the preparatory reactions in Table $V$ have been performed on the multigram scale. An effort was made to select those methods applicable to multigram preparations most useful to the experimenter, but the referenced publications deal with the entire range of micrograms to multikilograms.

Figure 6 shows a simple, but also effective, apparatus used for preparing fluorides. Nickel is the preferred furnare tube material; however, monel (an alloy of nickel, copper, and small concentrations of other elements) fittings, valves, and connecting tubing are satisfactory and are more readily available. Platinum "boats" or trays have served hundreds of hours in hydrofluorination reactions, but nickel has been preferred for use with hot fluorine. Excess hydrogen fluoride may be sparged from the furnace exhaust with aqueous potassium hydroxide. Fluorine is often diluted with an inert gas :c prevent excessive temperature rise from the heat of reaction. This gas mixture may be pumped in a closed loop to fluorinate some oxides because several percent of oxygen in the gas does not appear to affect reaction rates significintly. This recycling procedure alleviates problems of fluorine supply and disposal. Large quantities of fluorine may be disposed of by charcoal trappitug ${ }^{85,86}$ (there may be an explosion hazard!) and smaller quantities may be disposed of by trapping in beds of molecular sieve or soda lime (plugging problems to be expected). All apparatus components and trapping material must be closely monitozed for alpha artivity before disposal because fine powders or volatile actinide fluorides may be transported in the gas stream.

Halides other than the fluorides may be prepared in quartz or borosilicate glass apparatus, thus eliminating the risk of contamination by metallic impurities from the trays or furnace tubes of metal systems. Another advantage of glass apparatus is its transparency, which allows observation of progress of a reaction. Figure 7 shows an apparatus used on the 100-g scale for preparation of actinide halides. This design has been used (with halogenating agents other than fluorides) for preparing halides by reaction of oxides, oxalates, metal, 


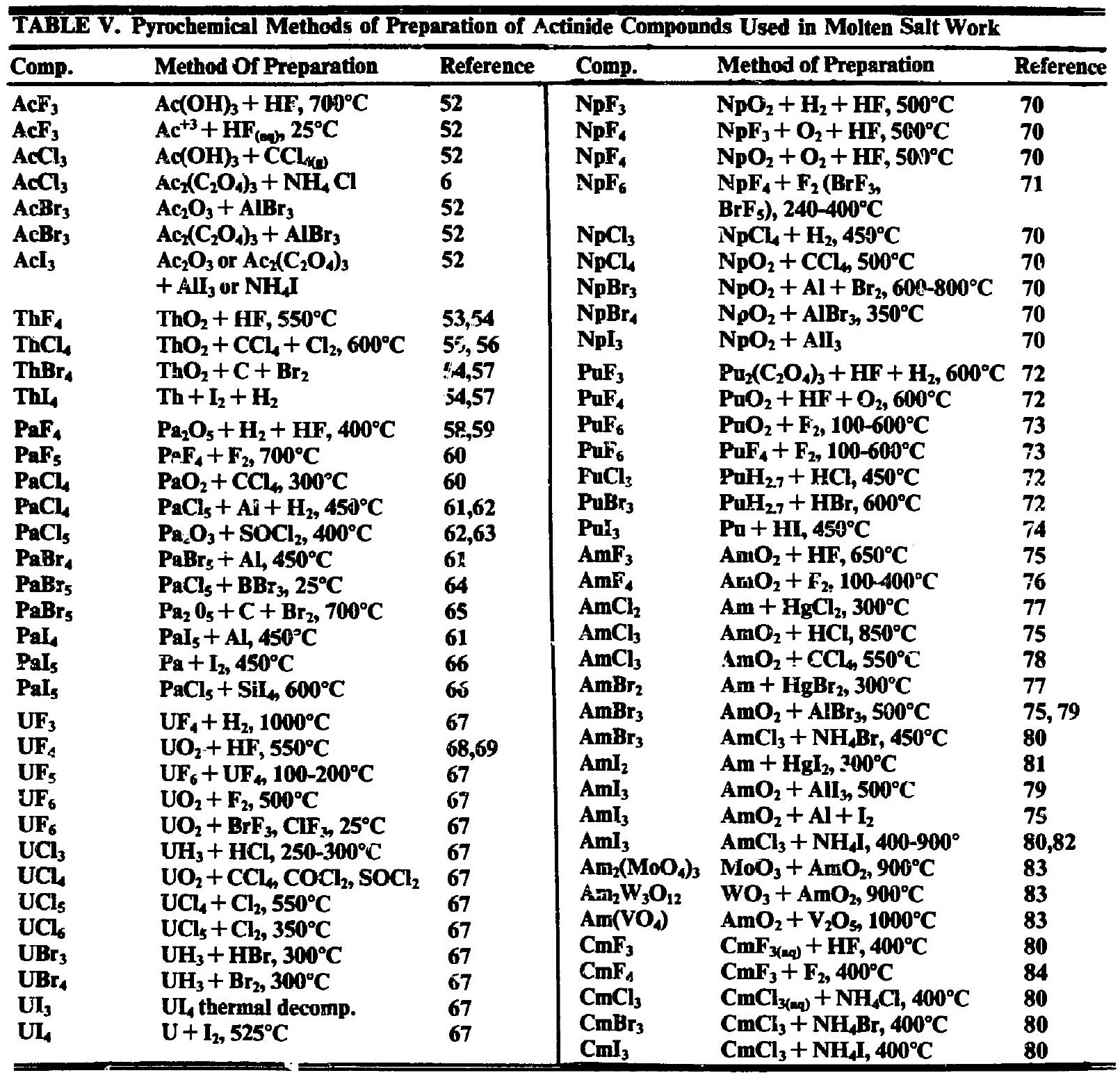



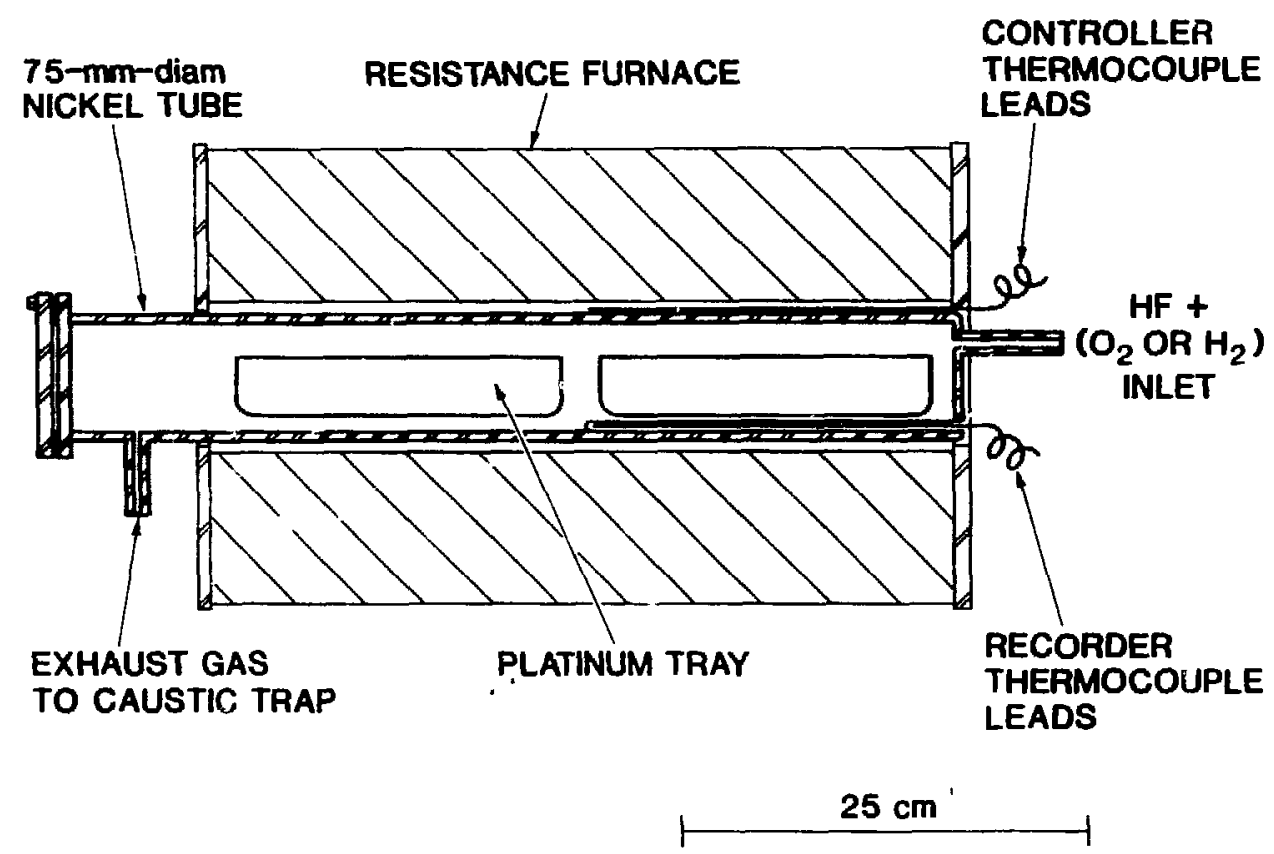

Fig. 6. Apparatus used for preparing up to $100 \mathrm{~g}$ batches of actinide fluorides.

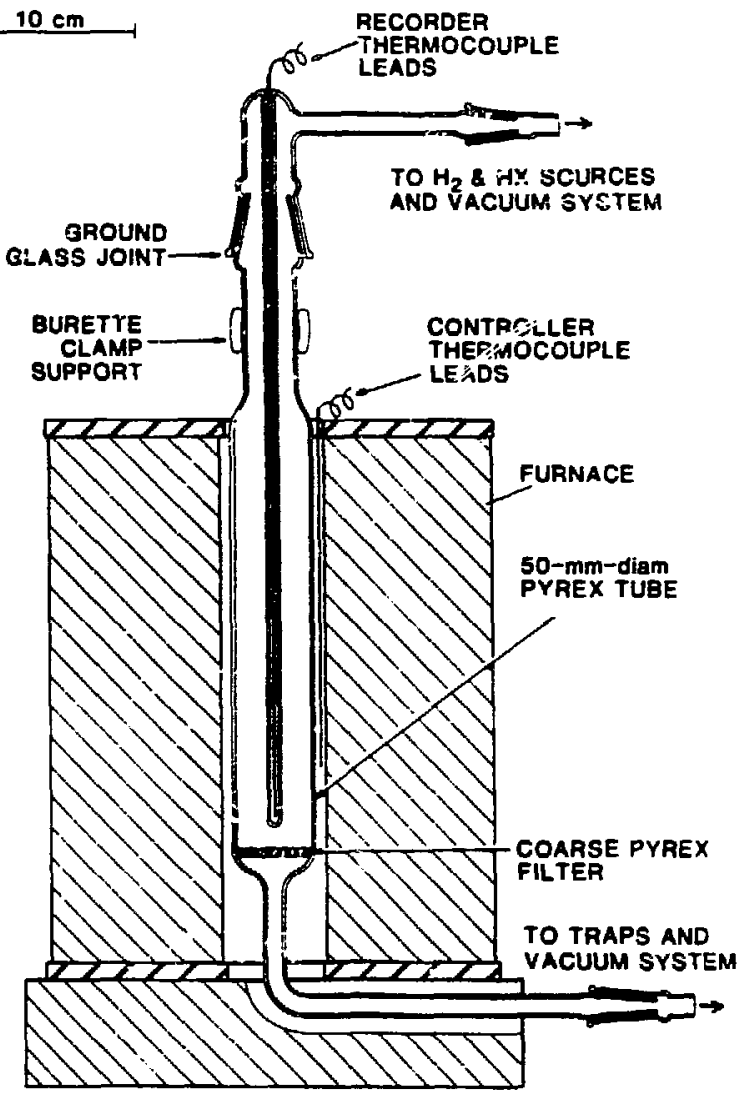

Fig. 7. Apparatus used for preparing actinide halides other than fuorides in batches of up to $100 \mathrm{~g}$ 
and hydrides. ${ }^{72}$ The system should be set up to allow either upflow or downflow through the furnace tube, although downflow is preferred to reduce channeling and to give more rapid and complete removal of reaction products (such as water) from the reaction zone. A major advantage of this design over that of the horizorital tube and tray is much more efficient use of the halogenating agent, thereby reducing the excess reagent disposal problem. In some instances, the actinide was introduced into the furnace tube as metal and was conyerisd to hydride, which was then thermally decomposed and converted to the halide. Hydride procedures are undesirable because of the hazards of handling hydrogen and the irreproducibility of hydride formation, but the halide produced may have lower concentrations of carbon and oxygen impurities, often present in halides prepared from oxalates or oxides.

2. Oxyhalide Preparation. Cxyhalides of actinides may hav : been present as imfurities in many molten salt studies or applications. bur intentional studies of oxyhalides in molten systems are very limited. ${ }^{87}$ These compounds can be prepared by several methods ${ }^{88-90}$ and have ben characterized by $t P($ chniques such as $x$-ray diffraction, although without corr plete chemical anaiysis to determine the purity rigorously. Pure oxyhalides probably are best prepared by treating pure powdered halides at controlled elevated temperatlises with a reactant such as:, 'yydrobalogen ci: rying a known ancicntration of water vapor. Protactinium seems to tend more toward oxyhalide formation ${ }^{90}$ than the other actinides do, and many of its oxyhalides have been ids nt:fieà.

3. Preparation of Other Oxycompounds. Other actinide oxycompounds such as sulfates and nitrates have been prepared by precipitation from or evaporation of aqueous solution. It is generally difficult to remove water of hydration from these compounds without decomposing theni. One altemative to preparing these pure compounds for molteli salt studies is dissolution of small amounts of other compounds (such as halides) in molten salts such as nitrate eutectics. The effect of the foreign anion may be negligible if the required actinide concentration is low. This may be true for studies such as observation of absorption spectra.

Another small group of oxygen-containing actinides has been prepared during phase diagram studies. ${ }^{2-5} \mathrm{Ap}-$ parently, iittle has been done with these compounds, other than preparation and characterization by applying $x$-ray diffraction techniques and microscopy. This group includes tungstates, molybdates, and silicates of thorium, neptunium, and uranium. Not all members of this cation/anion matrix have been prepared, and they are often considered part of pseudobinary systems with the correspording alkali metal compounds. For in- stance, the $\mathrm{NpO}_{2}-\mathrm{Li}_{2} \mathrm{O}-\mathrm{MoO}_{3}$ system is treated as the $\mathrm{Li}_{2} \mathrm{MoO}_{4}-\mathrm{Np}\left(\mathrm{MoO}_{4}\right)_{2}$ system. ${ }^{31}$ These compounds have been prepared by sealing such combination: as $\mathrm{Li}_{2} \mathrm{O}$, $\mathrm{MoO}_{3}$, and $\mathrm{NpO}_{2}$ in platinum tubes and holding them at elevated temperatures for extended periods.

\section{Final Sters of Purification}

Even though care is exercised to use the purest reageñts available in the actinide salt preparation and salts of the highest purity available are used as diluents, small amulnts of impurities that may affect experimental measurements often remain with the molten salt. Some of these can be removed by chemical or physical treatment (such as sparging with a hydrohalogen gas), even after they have been introduced into the apparatus for the observation.

1. Distillation Methods. Purification by distillation is easily applied to many of the halides prepared on the microgram-to-gram scale. An apparatus of the size used for these small batches is easily evacuated to very low pressures and is easily heated to the temperatures required for distillation. These distillations (or sublimations) are often accomplished by heating the salt in the furnace where it was formed and ccndensing it as at solid or liquid on the cooler walls of the furnace tube jusi oitiside the furnace. This inethod was used in the preparat 'on of the protactinium halides and oxyhalides, ${ }^{61}$ the nore volatile halides being distilled away from the oxyhaiides. However, distillation is not limiced to small batches. The simple apparatus she $n$ by rig. 8 was used io distill plutonium halide batches as large as $100 \mathrm{~g}$. The distillation tube was quartz, closed at one end, with an indentation halfway up the side of the tube to form a dam to contain the liquid product of distillation. The pool at the bottom of the fyrnace was maintained at about $900^{\circ} \mathrm{C}$ and the collected pool was at about $800^{\circ} \mathrm{C}$. Volatile impurities collected on the walls of the tube outside the furnace. Even larger quantities of more volatile halides cari be purified by distillation. Kilogram quantities of uranium hexafluoride are purified by vacuum distillation between traps alternately cooled by liquid ritrogen (or dry ice) and warmed to temperatures near ambient. Nickel, monel, graphite, and precious metals are used in constructing apparatus for handling the fluorides.

2. Sparging with Halogens or Hydrohalogens. The favored methods of preparing actinide halides often leave traces of oxide and oxyhalide in the product. Even if these compounds are absent during preparatinn, they may be introduced by exposure of the salt to air and water vapor. Diluent salts, including those that are not hygroscopic and do not have waters of hydration, 


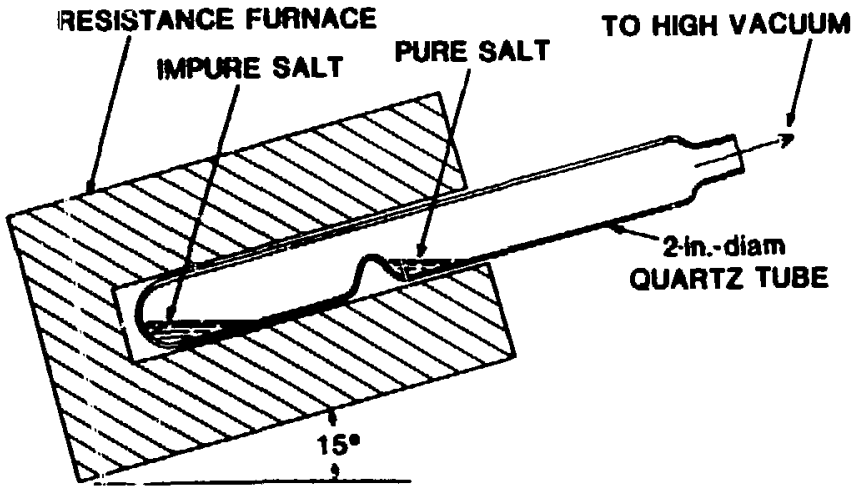

Fig. 8. Apparatus used for distilling actinide halides other than fluorides.

almost :Iways adsorb some water, which will form oxyhalid's when heated with actinide halides. The halides of cal cium, lithium, magnesium, and zinc are often used as dil 'uent or reactant in actinide molten salt work, and all oi these are difficult to prepare in truly anhydrous torm.

One example of rigorous purification is the method lsed for preparing salts for phase diagram experirrents with plutoniun trichloride, lithium chloride, and sodium chloride. ${ }^{2}$ Figure 9 sinows the apparatus used for removing water, oxychloride, hydroxide, oxide, and any material insoluble in the molten salt. The salt to be purified was in a quartz crucible in a quartz furnace tube. At the top wils a neoprene stopper through which passed a quartz thermocouple well, a quartz filisation assembly, arid a small tube for evacuating the furnace. tube. The most hygrcscopic salt (lithium chloride) was vacuum.dried during slow heating to $400^{\circ} \mathrm{C}$, then sparged with allhydrous hydrogen chloride during melting and for $30 \mathrm{~min}$ after melting. The molten salt was sparged briefly with argen to remove $\mathrm{HCl}$ as $\downarrow$ then filtered to remove black particulate material that was always observed when comnercially supplied analytical reagent lithium chloride was melted. An indication of the effectiveness of the treatment is that purified lithiun chloride could be held in quart: crucibles at $650^{\circ} \mathrm{C}$ for several days with no observable etching, whereas the same salt that had only been vacuum-dried etched quartz severely within a few hours. After experiments showed that thermal arrest temperaiures of these salts were the same when measured during sparging with argon and with hydrogen chloride, other otservations were made during sparging with hydrogen chloride to prevent buildup of any oxygenated species.

Others have used equally rigorous drying and hydrohalogen sparging techniques in preparing lithium chloride/potassium chloride eutectic for electrochemical studies. ${ }^{93}$ Recent attempts at Los Alamos to remove oxygen-containing species from kilogram quantities of calcium chloride $/ 10 \%$ calcium oxide mixtures by hydrochlorination at $850^{\circ} \mathrm{C}$ show great promise.
Hydrogen chloride appars to be more effective than phosgene. In another study, ${ }^{94}$ it was reported that chlorine was more effective than hydrogen chloride for preparing pure lithium/potassium chloride eutectic for electrochemical studies when the salt mixture was Ireated at $450^{\circ} \mathrm{C}$ but that the treatment with chlorine was not effective at $740^{\circ} \mathrm{C}$. When halogens are used for this purpose, the experimenter must avoid unwanted higher oxidation states of actinides because these have more volatile halides. Care must also be exercised to avoid container materiais that will react and contribute cationic impuritias to the molten salts.

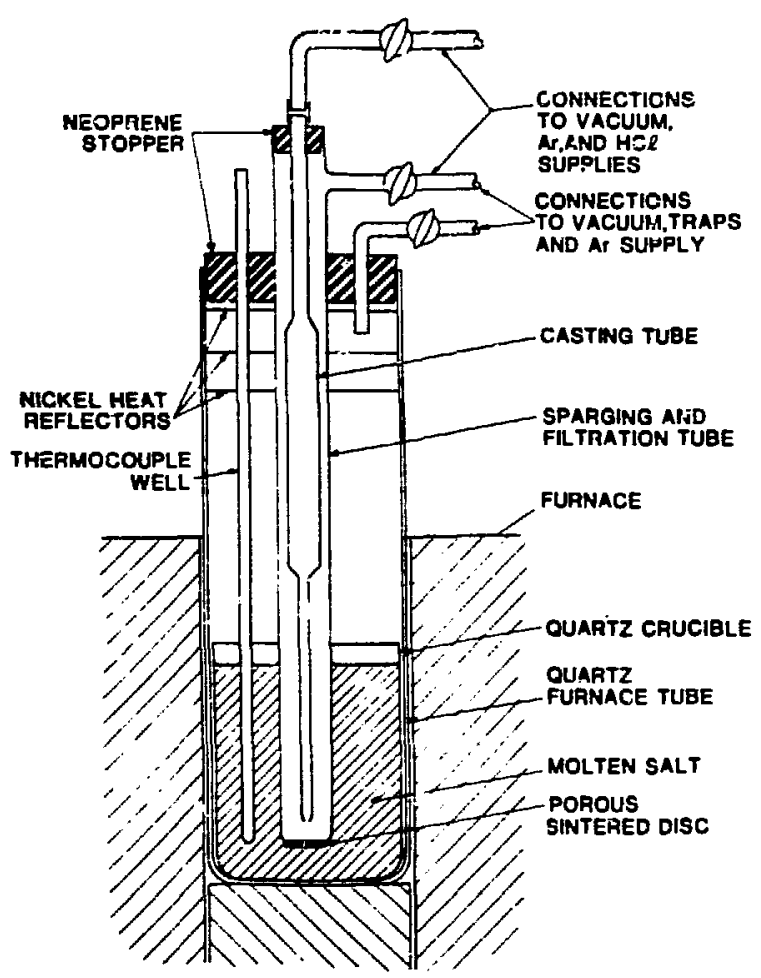

Fig. 9. Apparatus for purifying molten salts by sparging and filtration. 


\section{METAL PREPARATION AND PURIFICA- TION}

Actinide metals are prepared oy active metal reduction of oxides or salts and by electrorefining. The three general methods of active metal reduction are (1) reduction by metal vapor in a vacuum system, (2) reduction in a closed pressure vessel ("bomb" reduction), and (3) reduction in a closed vessel at ambient pressure. As normally performed for high yields, the reductions produce almost no separation of the actinide from metallic impurities, although the third method can be operated to produce low yield and some separation from impurities. Metals may sometimes be purified further by a process called molten salt extraction wherein the molten metal is equilibrated with a molten salt and the metal is purifisd by transfer of impurities to the salt phase.

\section{A. Reduction by Metal Vapor}

Originally, experimenters using microtechniques employed metal vapors to reduce oxides or salts to prepare all actinice metals except uranium and thorium..${ }^{95}$ These techniques are still used for preparing actinium and the trarscurium elements. ${ }^{96}$ The selection of the reductant to be used for these reactions is based on the free energies of formation of the compounds involved and the vapor pressures and meltirig points of the reactants and products. The free energies of forration of the candidate oxides at $725^{\circ} \mathrm{C}$ are iisted in Table III. Free energies of formation of these elements ${ }^{1}$ fluorides and chlorides at $725^{\circ} \mathrm{C}$ are listed in Table VI. These tabulations can be a guide in selecting the actinide compound and its reductant. For instance, potassium vapor reduced actinium trichloride, ${ }^{6}$ but it would not have reduced actinium oxide. As was pointed out in Sec. IV of this report, lithium vapor can reduce fluorides of nonvolatile curium and the resulting lithium fluoride can be volatilized away from the products. More volatile californium, however, may be lost when reduced by the same technique. ${ }^{96}$ Particular care must be exercised when working with micrograms of materials at high temperatures lest the entire sample be lost by allnying with the support or by vaporization during the experiment.

\section{B. Pressure Vessel or "Bomb" Reduction}

In the pressure vessel, or "bomb," reduction technique, a compound (usually an oxide or halide) of the actinide is mixed with a metal (usually an alkali or alkaline-earth metal) that will react to form a compound with a more negative free energy of formation than the actinide compound has. This technique is prominent in preparing actinides from their compounds, on both commercial and laboratory scales. The choice of actinide compound and reductant is based in part on the free energies of formation listed in Tables III and VI, but also important are the melting points, phase reiationships, viscosities, and vapor pressures of the feed

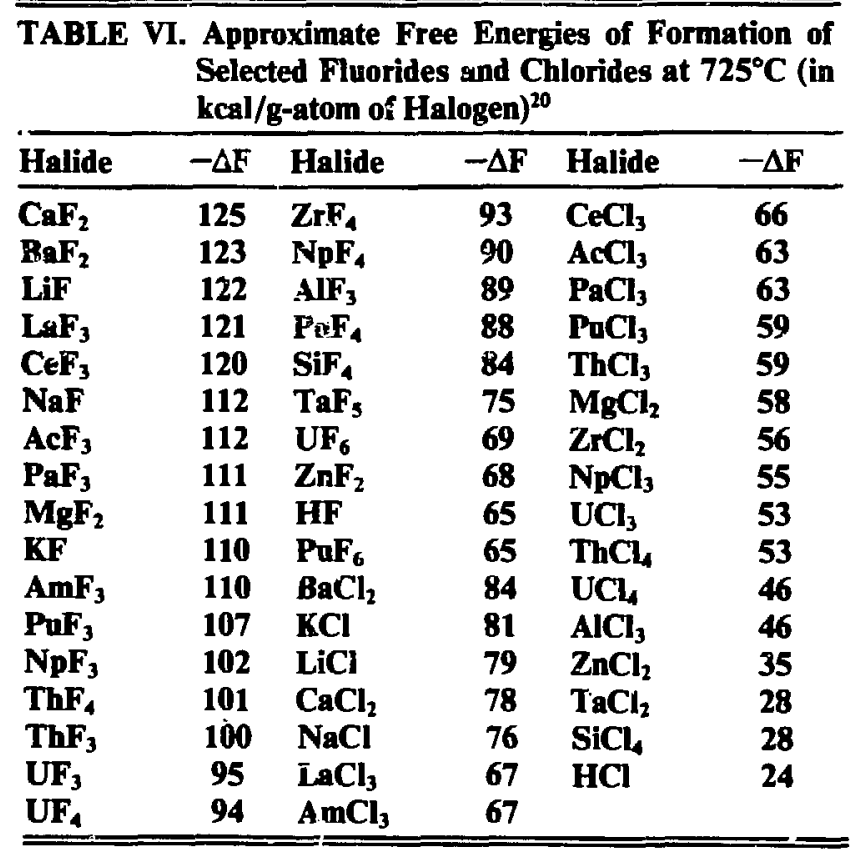


salts put into the charge and the product salts that form the slag. The latter must be separated from the metal product. The bomb consists of a metal container (usually steel) to withstand pressure and of a refractory liner (such as magnesium oxide, calcium fluoride, or fused dolomite) to resist chemical attack. The liner also furnishes both thermal and chemical protection from attack on the metal container. Excess reductant (about $25 \%$ above the theoretical amount required) is added to the mixture of salt and reductant to increase the man! yield. This excess ensures good contact with the compound being reduced (no stirring is provided other than that produced by the reartin itself) and reacts with traces of impurities stich as water and oxygen. A "booster." an element or compound that reacts just itiviti or during the early stages of the actinide reduction, is often added to the reactants. The mechanism of the booster in improving reduction yields is a controversial subject. One theory is that energy released from the booster reaction simply heats the products of reaction to a higher temperature at which the slag and metal are less viscous and flow more rapidly to allow better consolidation of the metal product. Another theory is that products of the booster reaction produce slag with a lower melting point, which provides more time for the metal to coalesce before the slag freezes. A third theory is that the booster triggers the reduction reaction at a lower overall system temperature than would be the case without it, so the maximum system temperature during reduction is lower, and less spattering and less reaction with the bomb liner occurs, thus producing higher yields. Any one, two, or none of these effects may occur during a reduction reaction. Many questions about the behavior of mol:en salt/metal systems during bomb reduction remain unanswered. It appears that performance of such reductions is an art rather than a science.

The actinide metals commonly produced by bomb reduction are thorium, uranium, neptunium, plutonium, and americium. Other actinide metals are usually produced by microtechniques because of the limitea availability of the elements or because of radiation problems in handling larger quantities.

Bomb reduction on the $100-\mathrm{kg}$ scale is used commercially for thorium and uranium metal production, although both metals have be $?$ ? produced commercially by reduction at ambient pressure in open containers. One method of producing thorium on the $100-\mathrm{kg}$ scale is reduction of thorium tetrafluoride by $25 \%$ excess calcium. Zinc chloride equal to $10 \%$ of the weight of the fluoride is added as a booster. The pressure vessel is steel with a fused dolomite liner. The charged and sealed bomb is put into a furnace preheated to $660^{\circ} \mathrm{C}$. The slag is reported ${ }^{97}$ to be $\mathrm{CaCl}_{2} / \mathrm{CaF}_{2} / \mathrm{ZnF}_{2}$ and the metal phase an alloy of thorium containing 4 to $7 \%$ zinc. After mechanical separation of the metal and salt phases, the zinc is distilled away from the thorium. This reduction reaction must be conducted by the bomb technique to prevent escape of zinc and zinc chloride, whose boiling points are exceeded during the reaction.

A similar bomb reduction method is used commercially to produce uranium on the $100-\mathrm{kg}$ scale. Uranium tetronnoide is blended with $5 \%$ excess magnesiurn anic loaded into a pressure vessel with a fusc: doiomite liner. The sealed bomb is put into a gasfired furnace preheated to $600^{\circ} \mathrm{C}$. The heat of reaction melts the magnesium chloride and uranium products, so they coalesce, making mechanical separation of the cooled products feasible. The pressure vessel is required because of the high vapor pressures of magnesium and magnesium chloride.

For molten salt studies it is probably more practical to obtain thorium and natural uranium metal and salts from a laboratory that produces these items commercially than to set up equipment for bomb reduction. On the other hand, much research is needed before the chemical mechanisms of boosted bomb reduction are understood. Because of many fewer health, safety, and security problems in work with thorium and natural uranium than in work with other actinides, these two elements are good candidates for such research.

A much smaller scale of bomb reduction is useci in preparing plutonium, neptunium, americium, and highly enriched uranium. Because of the intense radioactivity and the criticality constraints, bomb reductions of these elements are restricted to the 1- or 2-kg scale, except for americium, whose reduction has been limited to 25- 6 batches because of the gamrna and neutron radiation levels of americium tetrafluoride. The laboratory-scale (as contrasted to the cominercial-scale) bomb reduction technique developed rapidly from 1943 through 1946 and has evolved less rapidly since then. Figure 10 centains sketches of the pressure vessels used up to $1945^{98}$ compared with one of a pressure vessel currently used for preparing 2-kg batches of plutonium. The bomb reduction procedure of tile tetrafluorides has not changed greatly. The pressure vessels are steel and the lining crucibles are low-density magnesium oxide. The tetrafluoride is mixed with iodine (iodine-to-metal mole ratio is $0.15-0.30$ ) anr granular calcium $25 \%$ in excess of the amount required to react with the fluoride and iodine. This mixture is loaded into the pressure vessel, a magnesia lid is placed on the crucible, and the pressure vessel lid is firmly sealed to the body, using a copper gasket. The bomb is next evacuated and backfilled with argun to a pressure significantly above ambient for a leak check. The pressure is then reduced to ambient and the connecting orifice is closed. The integrity of the seal is important because high pressures (greater than $100 \mathrm{psi}$ ) are generated at the instant of reaction. If the argon escapes through a leak at the gasket at that instant, it is followed by a mixture of volatile 


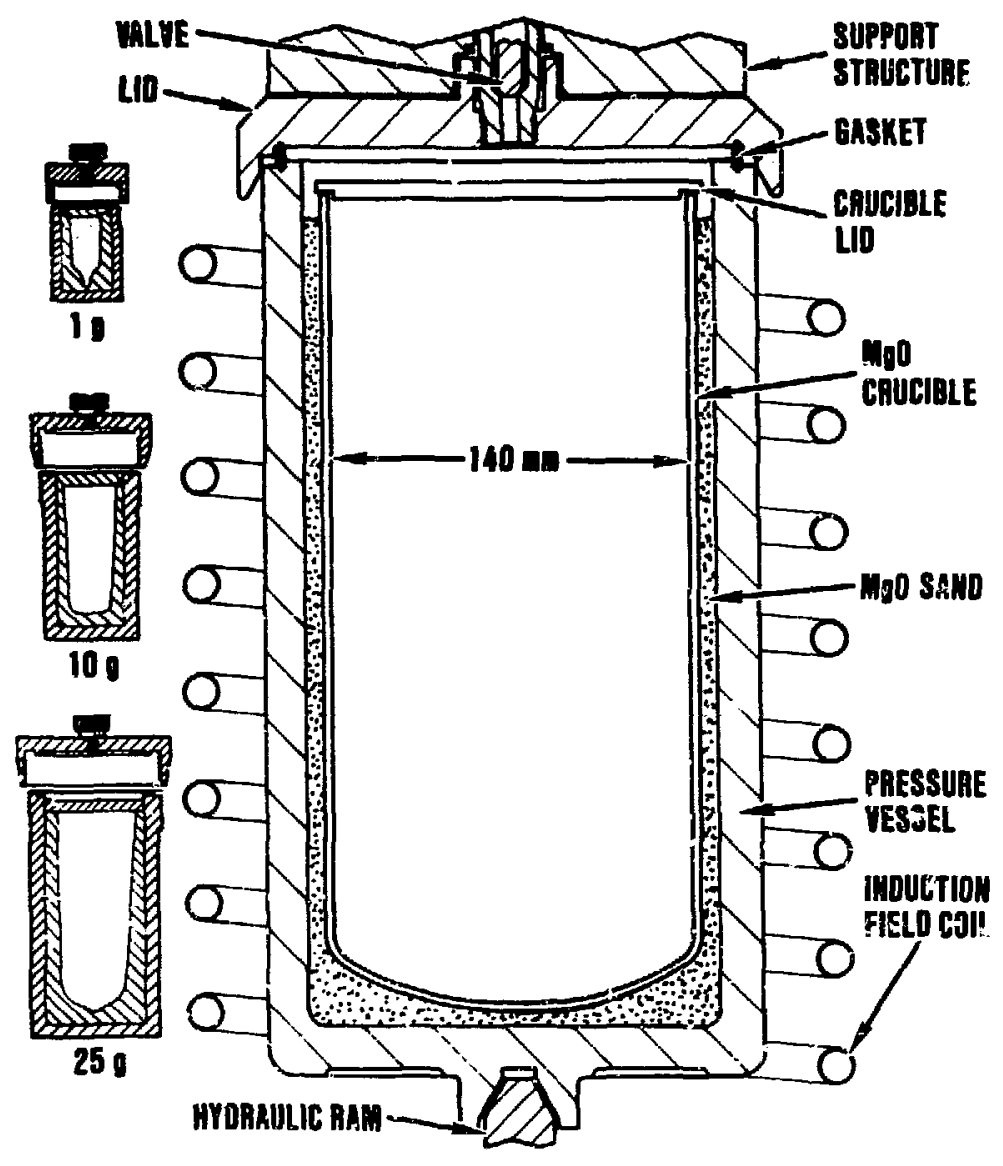

Fig. 1\%, Containers used for preparing actinide metals by "bom "' reduction of halides. All four contuiners are shown on the same scale. The three smali containers were used hefore 1945. The larger container is currently used for $2 \cdot \mathrm{kg}$ batch redurtions.

calcium, iodine, and magnesium (from the magnesia crucible) that instantly reacts to enlarge the leak and release la:ge quantities of actinide to the surroundings with explosive force. It can be seen from Fig. 10 that the earlier pressure vessels had lids held on by threads. A threaded plug closed a hole in the lid. In this design, after the bomb was loaded and sealed, the plug was removed and replaced by a threaded tube for evacuation 'nd argon filling. The tube was then removed and replaced by the plug before the bomb was heated. A hydraulic ram holds the lid of the modern large-scale bomb on the assembly. A valve for gas transfer control is m'sunted permanently in the lid. The bomb is heated by direct cr,apling of the induction field with the wall of the press'st: vessel. Reaction of the mixture is detected by minitoring the drop in neutron emission from the $f$ Jorine alpha-neutron reaction that diminishes when itcimate mixing of the actinide and fluorine is disIupted. Heating is discontinued when the mixture reacts if the charge is greater than $100 \mathrm{~g}$, but for smaller-scale reductions heating must be continued to about $1000^{\circ} \mathrm{C}$ to attain good separation of metal and salt. After reaction, the bomb is cooled and the cense motal regulus is mechanically separated from the slag.

\section{Ambient Pressure Reduction of Actinide Salts}

The distinction between bomb reduction and ambient pressure reduction of salts to form metals is often questionable. The major difference in the equipment is that the bomb reduction pressure vessel is always built sturdily and is sealed during the reaction, whereas ambient pressure reductions may be performed in fragile closed containers or even in open containers.

Ambient pressure rec': lower total energy reiease or a lower rate of energy release governed by the combination rate of reactants. No booster is necessary, although a small "ignitor" may be used. Neither volatile salts nor volatile metals are 
heated to high temperatures (above their boiling points) during these reactions.

1. Reductions by Active Metals. The procedures in commercial production of thorium and uranium at ambient pressure can hardly be distinguished from the bomb reductions discussed in Sec. VI.B. Natural uranium is produced on the $100-\mathrm{kg}$ scale by adding a burning pellet of potassium nitrate/lactose (no booster is used) to ignite a mixture of uranium tetrafluoride and excess calcium. ${ }^{99}$ Large-scale reductions of thorium tetrachloride by magnesium produce a thorium/magnesium alloy from which the magnesium is separated by distillation. Because these salt/metal systems oxidize badly at high temperatures in air, the reactants and products are blanketed with an inert gas until they are cooled.

Research- and development-scale (10 g of actinide) reduction can be conducted simply. Extensive experiments that resulted in the development of the "pyroredox" process ${ }^{100}$ for purifying plutonium were conducted with simple apparatus (Fig. 11), which consisted of a quartz furnace tube closed at the top by a neoprene stopper through which passed a quartz thermocouple well, a tube for evacuating the tube and backfilling with argon, and a quartz tube for reductant introduction. The granular reductant was in a rotatable arm of the latter tube, so it could be introduced gradu-

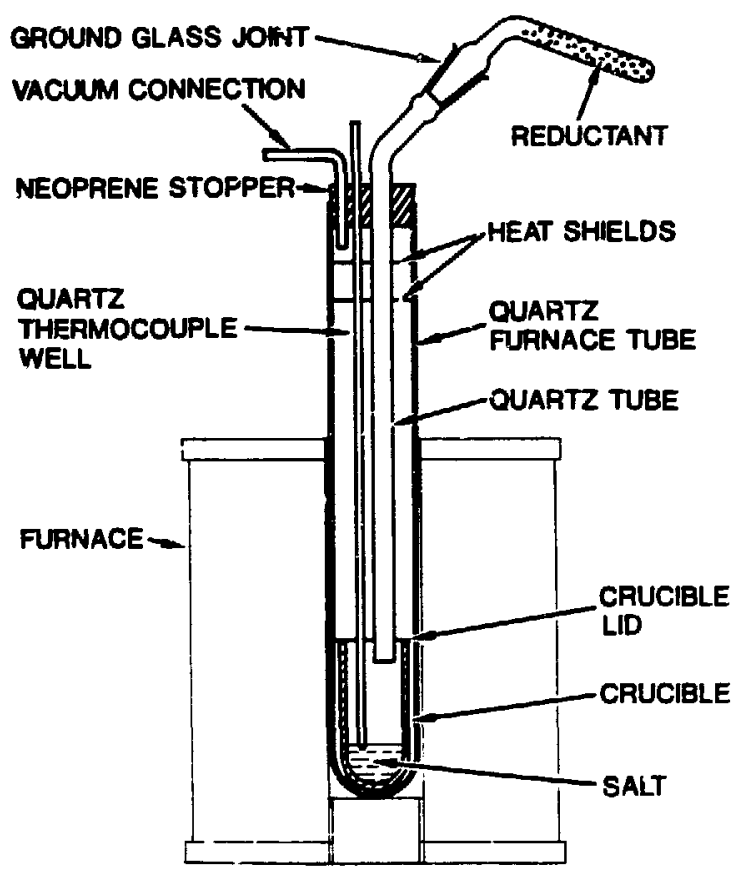

Fig. 11. Apparatus used for research and development studies of reduction of plutonium chloride. ally. The crucibles were quartz, magnesia/10\% titania, and tantalum. The salt was placed in a crucible that had been previously baked out in vacuo. The loaded crucible was quickly put into the furnace tube, which was evacuated briefly and then filled with argon. The rotatable side arm was removed, loaded with reductant, and returned to the position shown in Fig. 11. Furnace tube evacuation was resumed and the tube was put into the furnace, where evacuation continued during heating until the salt melted. The apparatus was then filled with argon while heating continued to the desired reaction temperature (up to $850^{\circ} \mathrm{C}$ ); the side arm was then rotated to gradually introduce the reductant. The salt studied most extensively was a plutonium chloride/sodium chloride mixture. Severe spattering occurred if calcium addition was too rapid, but the total charge of other reductants such as lanthanum and cerium did not produce spattering even if combined with the salt before heating. Thus, the reductant addition tube is unnecessary for some reductants. This apparatus was used to study the conversion of plutonium metal to plutonium chloride/alkali chloride combinations and reduction of the salt by several metals to form plutonium metal and alloys.

Some of the plutonium reactions studied in the simple quartz apparatus described above have been scaled up to the level of hundreds of grams ${ }^{101}$ with simple but sturdy containers. The design of an apparatus is shown in Fig. 12. The same general design has been used in various sizes, the largest having a crucible diameter of about $77 \mathrm{~mm}$ and a plutonium capacity for metal/salt reactions to about $1 \mathrm{~kg}$, the practical capacity for each reaction depending on the energy release during reaction. No reactant intr-duction tube has been provided, although such an addition would be rather easy. The stirrer is tantalum or tantalum/10\% tungsten. The thermocouple well is a closeri-end nickel tube inside a tantalum well. This combination resists oxidation on the inside and attack by the salt on the outside. Triple containment (in addition to the primary crucibie) prevents release of molten plutonium to the air of the glovebox enclosure. The secondary containmerit is a tantalum can nested inside a stainless stecl container. The furnace tube is an oxidation-resistant alloy such as Inconel or Hastelloy. Various supports, baffles, and insulators are used to reduce temperature gradients near the end of the furnace. The lower end of the furnace tube extends beyond the end of the resistance-heated furnace to a cooler region, so molten plutonium reaching this point would immediately freeze and not alloy with the metal of the tube. Ceramic crucibles often leak small amounts of molten salts and occasionally leak smali amounts of molten metal, but the tantalum secondary containment has never been breached.

The reactants and diluent salt are put into the crucible at room temperature. The crucible is then put into the 


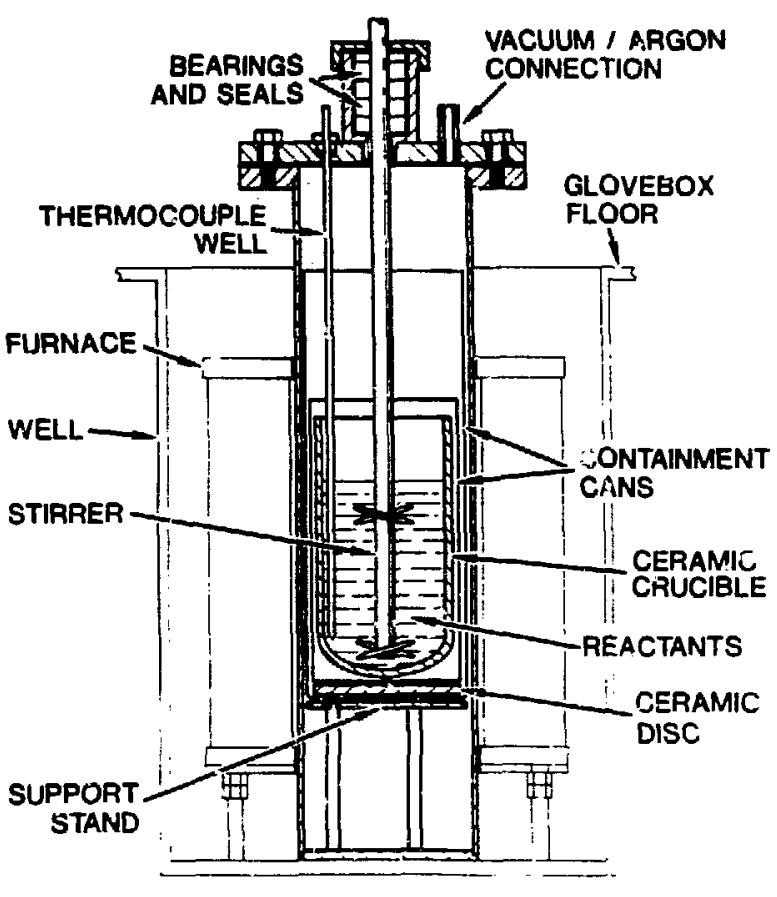

Fig. 12. Apparatus for ambient pressure oxidation and reduction reactions of up to $1-\mathrm{kg}$ batches of actinides in molten salt systems. The diameter of the cuter containment can is about $15 \mathrm{~cm}$.

nested cans of the furnace tube, and the lid of the furnace tube (with the thermocouple well and the stirrer in a raised position) is bolted into place. The tube is evacuated and checked for leaks, then filed and pressurized with argon. The furnace is heated to the melting point of the salt. The thermocouple well and stirrer are pushed into the molten salt and the desired heating and stirring are completed. The stirrer and the thermocouple well are then retracted to a ievel above the surface of the molten salt before the salt is cooled to solidification temperature. The cooled products are separated mechanically.

The apparatus in Fig. 12 has been used for several different metal/salt reactions. Plutonium metal is reacted with zinc chloride containing potassium chloride as a diluent to lower the melting point of the plutoniurn trichloride that is formed. This reaction is performed in a tantalum crucible from which the products can be removed mechanically. It has also bəen shown that this reaction proceeds satisfactorily in quartz containers. ${ }^{100}$ The plutonium chloride/potassium chloride is then reduced by calcium metal in a vitrified magnesia crucible in the same apparatus to form plutonium metal. Another reaction conducted in a vitrified magnesia crucible in this apparatus is reduction of plutonium dioxide by granular calcium metal in molten calcium chloride. The amount of calcium chloride is such that the calcium chloride/calcium oxide product has a relatively low melting point compared to the usual maximum temperature of $875^{\circ} \mathrm{C}$.

Another reduction procedure that does not have as its goal the preparation of a specific metal, but rather the removal of all actinides from a given batch of salt, is "salt stripping." The impetus for such a procedure is peculiar to the actinides because of the discard limits and disposal expense for radioactive wastes. Examining the free energies of formation of the chlorides listed in Table VI leads one to prediat that actinides could be stripped from salts such as calcium chloride or sodium chloride/potrssium chloride by calcium metal. One could also predict that sodium would also be reduced, but the uncertainties of the values listed in Table VI do not justify a definite prediction of the extent of sodium reduction. Sodium reduction can be restricted by limiting the amount of added calcium. The salt-stripping process and the apparatus shown in Fig. 12 have been used successfully to strip plutonium and americium from chlcride processirg salts.

2. Electrolysis. Thorium, ${ }^{102}$ uranium, ${ }^{103}$ and plutonium $^{104}$ metals have been prepared by electrolysis of molten salts on various scales up to multikilograms. The most common procedure is electrolysis of the actinide chloride or fluoride in a mixed-chloride bath contained in a graphite crucible anode. The metal is deposited on a molybdenum cathode. Molten salt bath compositions include sodium chloride/potassium chloride and sodium chlorioe/calcium chloride. Thorium ard uranium have been added as $\mathrm{KThF}_{5}$ and $\mathrm{KUF}_{5}$ prepared by aqueous means. All three actinides have been introduced as pure anhydrous chlorides and flıorides. The cell must be designed so that chlorine gas produced at the ancde does not contact the metal deposit on the cathode. The metals are deposited as dendrites, which must be leached free of salt by aqueous means to recover the possibly pyrophoric metal powders. This method of metal production may significantly separate the actinide from active metals, such as the rare earths, but it has not become a popular process.

\section{Pyrochemical Purification of Actinide Metals}

The pyrochemical purifications discussed here apply to removal of impurities when the feed material is a metal and when the desired product is metal of higher purity. These methods can remove virtually all of certain impurities from actinide metals.

1. Electrorefining. In molten salt electrorefining, an impure metal is oxidized at an anode, transported through a molten salt electrolyte, and deposited as a pure metal ( $>99.95 \%)$ at a cathode. Figure 13 shows the 


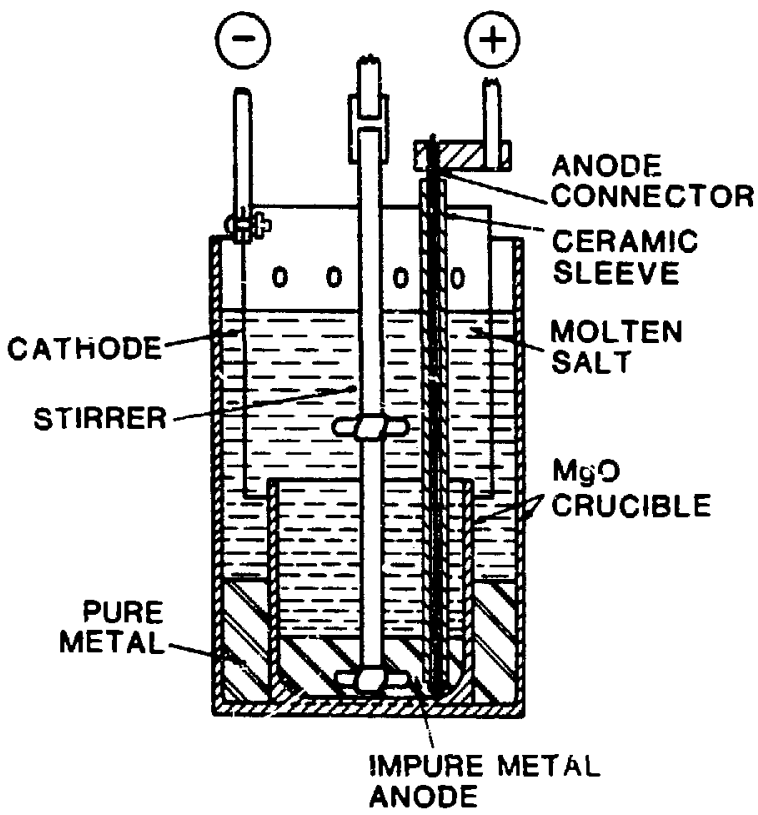

Fig. 13. Molten salt electrorefining cell.

cross section of a cell that has been used to produce highpurity plutonium on a multikilogram scale. ${ }^{105}$ The container is a cylindrical vitrified magnesia crucible with a smaller anode "cup" in the center. A vitrified magnesia stirrer stirs both the impure molten plutonium anode and the sodium chloride/po:assium chloride/plutonium chloride electrolyte. A magnesia-insulated tungsten rod dipping into the anode pool provides electrical contact. Pure liquid plutonium deposits on the cylindri a! tungsten cathode and drips into the ring-shaped space beneath it. The cell is operated at $740^{\circ} \mathrm{C}$ in a furnace tube with nested containers similar to those shown in Fig. 12. Loading, closing, evacuating, argon filiing, and stirrer, electrode, and thermocouple well manipulating are similar to those Sor the furnace in Fig. 12. Stirring the anode and electrolyte 'nd providing a large cathode surface area mirimizes polarization effects. The cell current is automatically interrupted momentarily at preset time intervals to measure the back electromotive force (EMF, which is an indication of polarization and/or excessive impurity concentration in the anode), and the current is discontinued if this EMF rises above a preselected value. This procedure maintains high purity of the product.

The higher melting points of the other actinide metals probably make electrorefining, as described above, practical only for plutonium and neptunium. Good purification of high-meiting metals can be attained in a molten salt electrolyte system using an anode that is an alloy of the high-melting metal dissolved in a low-melting metal such as cadmium or bismuth. The pure metal deposits on the cathode as a solid that can be recovered by dissolving away the salt electrolyte or by melting the metal so the salt floats to the top.

2. Molten Salt Extraction. The process referred to as molten salt extraction here has been called halijie slagging, chloride slagging, and molten salt/metal cquilibration. ${ }^{106-108}$ It consists simply of agitating molten salt and molten metal together in a container until an equilibrium distribution of the elements of interest is established. The system is then cooled and the metal and salt phases are separated mechanically. The apparatus is the same as that shown in Fig. 12. The crucible and stirrer materiais are selected for the combination of physical and chemical properties that best satisfy the purposes of the procedure. For instance, ceramic crucibles will probably participate in chemical reactions more readily than do tantalum crucibles, but the reaction products generally can be more easily removed mechanically from ceramic crucibles.

Molten salt extraction is used mostly for removing small amounts of active metal impurities from selected actinide metals. The capabilities of the technique may be predicted by using the free energies of formation of halides listed in Table VI. Elements having halides with more negative free energies of formation than those of the major component of the metal phase should be extracted into a salt phase containing an excess of the major metal halide. For example, it would be predicted initially that rare earths, actinium, protactinium, americium, plutonium, neptunium, and thorium would be extracted from uranium metal equilibrated with a molten fluoride eutectic containing a few mole per cent of uranium fluoride. This process might be impractical. however, because the high melting pcint of uranium would require a high operating temperature, which might not be tolerated by any available compatible container material. One way to avoid the problem caused by high temperatures is to dissolve the metal in a low-melting metal such as cadmium during processing and to distill away the volatile cadmium after extraction. Predictions of extraction behavior become even more uncertain when the alloying technique is used because one must deal with not only the uncertaintics in the free energy of formation values but also activity coefficients in the molten salt and in the alloy.

Molten salt extraction is important in the removai of americium from plutonium. ${ }^{46,47}$ Kilogram amounts of plutonium containing (typically) $3000 \mathrm{ppm}$ americium are contacted with low-melting potassium chloride/sodium chloride/plutonium trichloride in a magnesia crucible in the apparatus shown by Fig. 12 . The plutonium halide is either added as plutonium tetrafluoride or trichloride or is generated from the 
me al by addition of magnesium chloride. Approximately $90 \%$ of the americium is transferred from the metal to the salt phase.

During development of the americium extraction process, Mullins et al. developed an interesting sampling tect: ique $^{106}$ for sampling molten salt and metal phases to determine the americium distribution. Tantalum dippers were lowered individually into the metal phase to retrieve multiple metal samples at different times and temperatures without cooling the furnace. Similarly, the experiments took multiple salt samples by lowering nickel capsules having a sintered nickel filter in the bottom end (the top end was sealed) into the salt and pressurizing the space above the salt to force molten salt through the filter into the capsule. Salt and metal samples were withdrawn into the cooler upper part of the furnace to solidify them immediately after sampling. All samples were removed from the cool apparatus for analysis after the experiment.

Measurements of actinide distributions between molten magnesium chloride and zinc/magnesium alloys were made in a somewhat similar fashion to develop molten salt extraction methods for separating actinides from each other and from fission products. ${ }^{107-110}$

\section{PHYSICAL PROPERTIES MEASURE- MENTS}

New instruments for measuring physical properties of molten salt systems are increasingly available. New methods of data acquisition and analysis are being developed and implemented. No attempt has been made by this author to survey catalogs of scientific supply companies to obtain descriptions of new physical-properties-measuring equipment that might succeed (but have not been proved) in measurements on actinide salts. Some of the techniques discussed here may have been applied as many as 40 years ago. This approach may make the discussion seern outdated, but one defense of the approach is that the techniques successfully generated reliable data in almost all cases.

\section{A. Melting Points and Phase Relationships}

It was pointed out in Section 1 and Table I that one compilation $^{2-5}$ included phase diagrams of approximately 76 actinide oxide systems and 77 actinide salt systems. No attempt will be made to discuss all of those systems here; techniques and container materials used in typical studies will be described briefly.

One of the most comprehensive programs for determining phase relationships in molten salts was the Oak Ridge study of binary and ternary fluoride and chloride systems, in support of the Molte-: Salt Reactor experiment.9 The halides studied were primarily those of uranium ${ }^{111,112}$ and/or thorium ${ }^{113,114}$ mixed with halides of alkali and alkaline-earth metals. For thermal analysis, the fluoride salts were typically contained in nickel or graphite crucibles with as many as four crucibles in a single furnace tube."' Nickel stirrers whose vertical shafts passed through close-fitting graphite sleeves in the lid of the assembly were used to homogenize the molten salts. A slight positive pressure of helium was maintained inside the furnace tube to prevent reaction of the contents with air. Salt temperatures were reasured by chromel/alumel thermocouples in nickel thermocouple wells and recorded by strip chart recorders. Typical samples weighed $50 \mathrm{~g}$ and cooling rates were $3^{\circ} \mathrm{C}$ to $4^{\circ} \mathrm{C} / \mathrm{min}$. Little use was made of differential thermal analysis. Phases in quenched samples were identified by examination with a polarizing microscope and $x$-ray diffraction. As many as 20 to 30 quenched samples were prepared at one time by loading the crushed powders into a thin-walled nickel tube $0.10 \mathrm{in}$. diameter by 5 to 6 in. long. The tube was crimped at about 0.2 -in. intervals while being loaded, and the ends of the tube were sealed to protect the samples. Tubes were then heated in a furnare with a thermal gradient and dropped into an oilquenching bath. The tube was retrieved and samples were recovered after the compartments were cut open.

Different techniques were developed at Los Alamos for study of phase relationships of plutonium trichloride in binary combinations with alkali and alkaline-earth chlorides. ${ }^{92,115-117}$ Much greater effort was expended to remove traces of water and oxygen species from the salts and to prevent contamination by these species during observations. The purification method was described in Section V.C.2; the apparatus is shown in Fig. 9. The apparatus for thermal analysis and differential thermal analysis (Fig. 14) consisted of a 50-mm-diam, 38-cmdeep quartz furnace tube, closed at the top by a neoprene stopper that supported two $16-\mathrm{mm}$ - Jiam, 45$\mathrm{cm}$-deep quartz tubes. One of the quartz tubes contained the salt; the second contained either a similar amount of lithium chloride/potassium chloride or an empty ceramic crucible with a similar heat capacity and insulating effect. These smaller tubes were closed at the top by neoprene stoppers penetrated by quarz tubes that acted as thermocouple wells, gas sparging tubes. evacuation ports, and salt addition tubes. The salts were sparged with anhydrous hydrogen chloride during measurements (test measurements showed that thermal arrest temperatures were the same for hydrogen chloride-sparged and argori-sparged salts) to mix thoroughly during freezing and to prevent formation of traces of oxychloride. NG etching of the quartz was observed even after several Jays of operation at $450^{\circ} \mathrm{C}$ to $650^{\circ} \mathrm{C}$ with hydrogen chloride sparging. Inadequately dried salts containing a high concentration of lithium 


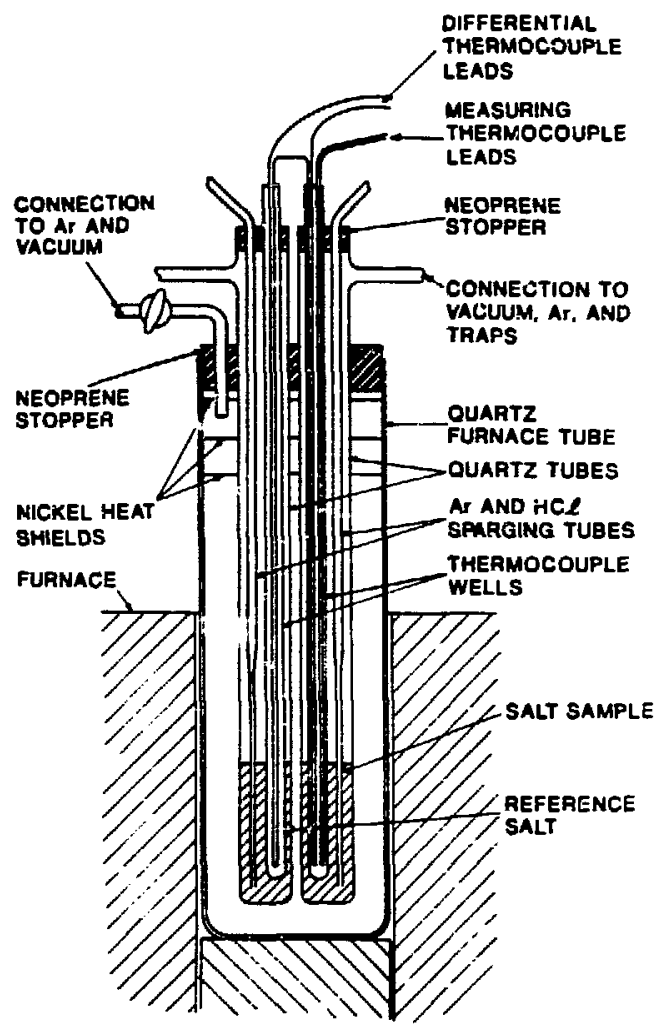

Fig. 14. Apparatus for differential thermal analysis of molten salts.

chloride etched quartz severely within a few hours at $650^{\circ} \mathrm{C}$ with argon sparging. Temperatures measured by chromel/alumel thermocouples and temperature differences between the two salt containers as measured by opposite chromel/alumel thermocouples were recorded by synchronized strip chart recorders. Differential thermal analysis indications were extremely helpful. Sample sizes were about $20 \mathrm{~g}$ and linear heating rates varied from $1^{\circ} \mathrm{C} / \mathrm{min}$ to $8^{\circ} \mathrm{C} / \mathrm{min}$. Microscopy and $\mathrm{x}$-ray diffraction techniques identified species in various mixtures. In one of the systems, part of the liquidus curve was too steep to be determined reliably by differential thermal analysis. ${ }^{87}$ Chemical analyses of samples taken through a sintered tantalum filter were used to determine liquidus compositions at selected temperatures.

In other techniques used for determination of phase relationships in actinide oxyanion systems, the compounds are often prepared by mixing the actinide oxide with oxides of tungsten or molybdenum and an alkali metal oxide, sealing the mixtures in platinum tubes, and annealing them at elevated temperatures. The products of annealing are studied by microscopy, $x$-ray diffraction, absorption spectra, and thermal analysis to determine phase diagrams of molybdates and tungstates.
Only limited descriptions of the techniques have been published. ${ }^{91,118-120}$

A simple differential thermal analysis apparatus ${ }^{121}$ using optical sensors has been used for determining phase relationships of the more refractory compounds of actinides at $800^{\circ} \mathrm{C}$ to $3200^{\circ} \mathrm{C}$. Figure 15 shows the apparatus. An induction heating unit supplies power to heat the furnace susceptor, which acts as an oven for heating the crucible containing the sample. The powe. supply can be programmed to increase or decrease its output at selected rates. A simple optical system delivers light from the incandescent furnace to an optical pyrometer and to two photodiodes. Light from the blackbody hole in the sample container is focused on one diode; light from a nearby part of the oven is focused on the other. Electrical signals proportional to temperature and to the difference in temperatures are amplified and recorded on a dual trace recorder. The experimenter uses the manual optical pyrometer to calibrate the recorder temperature trace during each heating and cooling cycle. Five materials whose melting points are well known (copper at $1083^{\circ} \mathrm{C}$, platinum at $1770^{\circ} \mathrm{C}$, rhodium at $1960^{\circ} \mathrm{C}$, alumina at $2050^{\circ} \mathrm{C}$, and iridium at $2440^{\circ} \mathrm{C}$ ) were used to check calibration of the system.

\section{B. Other Physical Properties of Actinide Salts}

1.Vapor Pressure. Numerous techniques have been applied in determining vapor pressures of solid and liquid actinides and their salts. The general methods are use of a direct-reading gauge, boiling at reduced pressure, transpiration, and Knudsen effusion. In many measurements on actinides, the apparatus was set up as in observations of nonactinides except for being partially or totaily enclosed in a hood or glovebox. Support electronics such as amplifiers and power supplies are often separated from the sensing units for glovebox work, even though the supplier of a commercially available unit may package the entire apparatus in a single cabinet. Special feedthroughs may be required to connect the sensor inside the glovebox to the amplifier outside the glovebox, but this extra effort may pay rich dividends in reduced maintenance problems of the electronics units.

The simplest apparatus for vapor pressure measurements is the direct-reading gauge, which may be of the Bourdon type, a diaphragm gauge whose output is read electronically by change in strain or capacitance, a nulldiaphragm gauge with automatic or manual balancing gauge, or a null-type sickle gauge with manual balancing. All of these direct-reading gauges have been used in measuring the relatively high (at ambient temperatures) vapor pressures of the hexafluorides of uranium, plutonium, and neptunium. ${ }^{122-124}$ The major constraint is that 


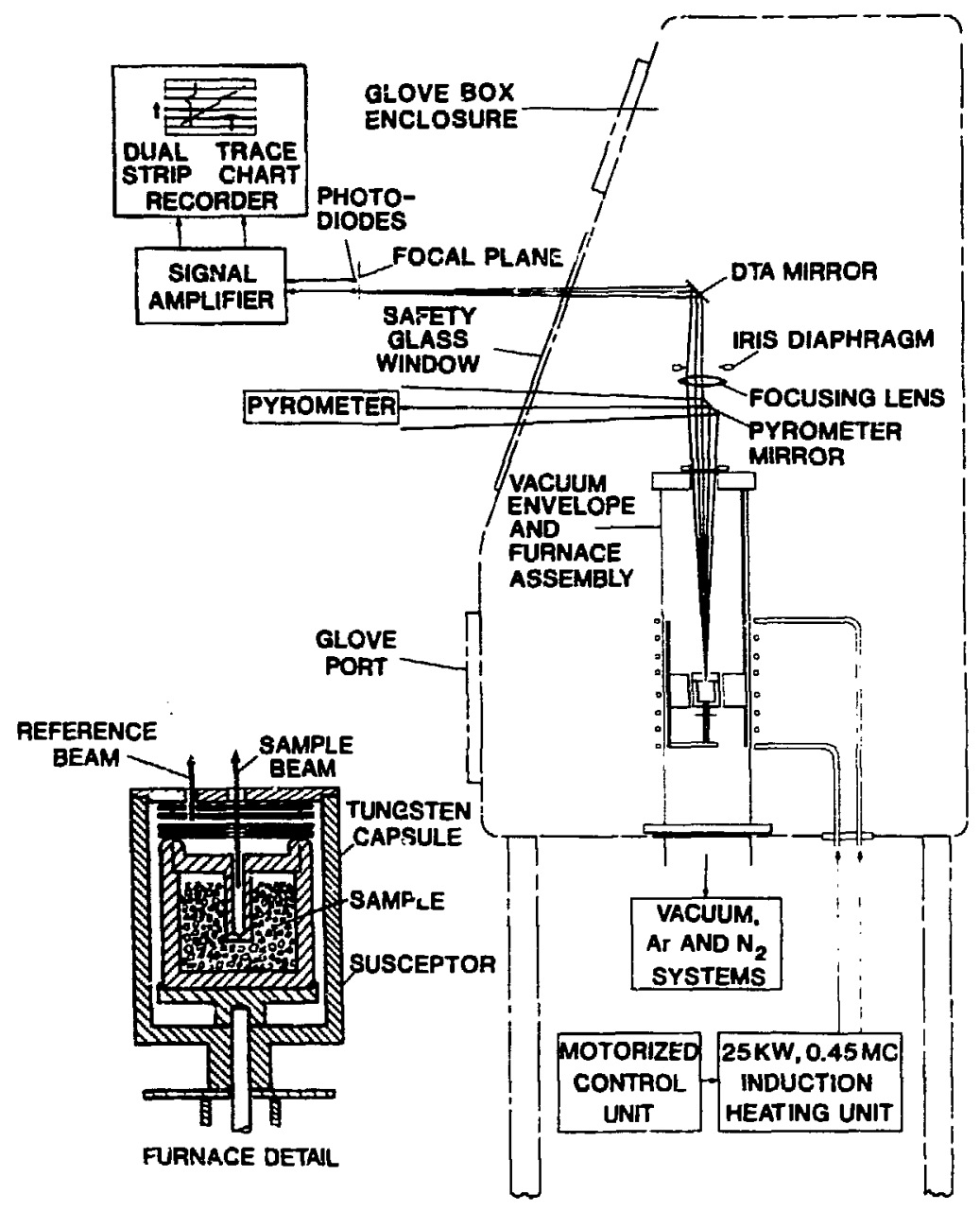

Fig. 15. Apparatus for differential thermal analysis of actinide compounds at temperatures up to $3200^{\circ} \mathrm{C}$

the gauge or null diaphragm must be held at a temperature higher than that of the sample to avoid condensation in the sensing element. An additional complication in the study of plutonium hexafluoride is its thermal and radiolytic instability. Buildup of fluorine pressure introduces errors in the measurement, and plutonium deposits on all interior surfaces contaminate the sensor.

Observation of boiling points under a reduced pressure of inert gas is another method for determining vapor pressures at high pressures (above about 25 tor:) and at temperatures harmful to the direct-reading gauges described in the preceding paragraph. ${ }^{125}$ The salt is heated in a reservoir of a system containing an inert gas at a pressure higher than the vapor pressure at the temperature of interest. The reservoir is held at the given temperature as the inert gas is very slowly pumped out of the system. Temperature variations of the liquid are observed with a very sensitive null instrument ni differential thermocouple system. When the vapor pressure is reached, boiling will be initiated and the temperature will dccrease slightly. The valve to the vacuum system is quickly closed (manually or automatically by actuation of a solenoid valve) and the pressure and temperature are noted. This procedure is repeated for all temperatures of interest. To avoid "bumping" of the liquid, a very slow flow of inert gas can be introduced by a capillary or porous tube dipping into the liquid. A variation of this method, called "quasi-static,"126 uses a heated salt reservoir with two restricted tubing connections at its top, a rather limited free volume inside the reservoir, and a large liquid surface. A significant le'sgth of the connecting tubes must be inside the furnace to reduce condensation of the sample. One of these tubes leads to a manometer or sensitive pressure gauge and the other leads to a vacuum system through a needle valve. Somewhere outside the furnace the two tubes are 
connected by a sensitive differential manometer. Similarly to the operation of the reduced-pressure, boiling-point apparatus, the system is filled with inert gas and heated to the desired temperature, and small aliquots of gas are removed. The differential manometer will show tem.porary differences in pressure as the aliquots of gas are removed but will return to the null point until the pressure reaches the vapor pressure of the salt. Then the differential ir anometer will show a "permanent" differential pressure, and the pressure indicated by the gauge is taken as the vapor pressure at the temperature of the liquid. It is claimed that this method is more sensitive than the reduced-pressure, boilingpoint method for vapor pressures below about 30 torr. ${ }^{126}$ The quasi-static and boiling-point methocis have been used for measuring vapor pressures of uranium tetrafluoride, ${ }^{127}$ thorium tetrafluoride, ${ }^{128}$ and other salts ${ }^{129}$ of interest to the Molten Salt Reactor program.

The transpiration or flow method of measuring vapor pressures probably requires the simplest equipment. It consists simply of flowing a carrier gas over the surface of the sample contained in a "boat" or crucible in a (generally horizontal) furnace tube. It is important that the carrier gas flow be slow enough for saturation and rapid enough that back diffusion and sample loss are not allowed. The transported sample must be measured accurately, either by weight loss or by complete recc. very of the condensed product. This method was used for determining vapor pressures of uranium tetrachloride ${ }^{130}$ and of thermodynamic quantities for plutonium tetrachlonide, ${ }^{131}$ which exists only under a chlorine atmosphere at elevated temperatures.

Knudsen effusion has been applied widely in vapor pressure studies of actinide compounds and elements. Tantalum and tungsten have been used for effusion ovens heated by either induction or resistance methods in high vacuum. The effusion orifices have been made by machining of thin sheets or larger blocks of metal. The ovens have been used both with and without inner cups, which have been tungsten, tantalum, or ceramic, with and without chemical vapor-deposited tungsten coatings. The greatest advantage of using the inner cup is limiting creep by the liquid samples. Creep may lead to change of orifice diameter and cause sealing of the lid on the oven, thus preventing reuse. The inner cup shouid have a sharp lip at the top to prevent or reduce creep of the liquid to the outside of the cup. The oven and its heater should be designed so that the orifice and lid operate at temperatures slightly higher than those at the bottom of the crucible so the sample does not redeposit on the lid and orifice.

The vapor pressure is determined from calculations based on the rate of effusion from the orifice. This is, in theory, most simply determined by measuring the weight lost in heating the oven and contents for a specific time at a specific temperature. However, there are much more rapid methods for measuring rates of effusion. One of these is measurement of the sample deposited on a target within precisely controlled geometrical constraints. Several targets are loaded into a holder in the vacuum system. A target-changing mechanism enables collection of several samples during a run without opening the vacuum system or cooling the Iurnace. Liquid nitrogen or chillec' water often cools the target holder to ensure that the condensation coefficient is unity.

Radioactive materials are uniquely suited for vapor pressure studies by target collection because submicrogram quantities of samples collected on targets can be measured quantitatively by applying counting methods. Inherent in this method is the assumption that the identity of effusing species is known. This can be assured by adding a mass spectrometer to the system to identify species. A mass spectrometer can determine vapor pressures by ion current measurement without a target collection system if an elaborate calibration scheme involving multiplier gain, isotopic abundance, ionization cross sections, and threshold energies is used. $^{132}$

Vapor pressures for plutonium halides, plutonium oxide, and americium metal determined by target collection and counting were published in 1950. ${ }^{133-135}$ The same method, but quite different apparatus, has been used for determining vapor pressures of the fluorides of plutonium and americium. ${ }^{136}$ Excellent discussions of the technique are given in articles describing vapor pressure determinations for several actinide metals by Knudsen effusion. ${ }^{137-139}$

2. Surface Tension and Density. The two most popular techniques for measuring surface tension of molten salts can be modified slightly to measure density in the same anparatus. Over $80 \%$ of the measurements of surface tension are by the maximum gas bubble pressure technique, ${ }^{140-142}$ in which a capillary tube with a precisely frrmed tip is immersed to an accurately determined depth in the molten salt and pressurized with a very slow gas flow to form bubbles at the rate of $\leq 5 / \mathrm{min}$. The inside diameter of the capillary is about 1 $\mathrm{mm}$ and must be very nearly a perfect circle. The end must be flat and perpendicular to the axis of the capillary. Opinions differ as to whether the edge of the orifice should be a "knife edge" or a "small flat." These capillaries have been made of precious metals and refractory oxides such as beryllium oxide. The surface tension is calculated from the depth of immersion, the inside diameter of the tube, the maximum pressure observed during bubble growth, and the density of the liquid. The liquid density can be measured by noting the change in maximum pressure with an accurately measured change in immersion depth of a single capillary, or by difference in maximum pressures for 
two capillaries with accurately known differences in immersion depth in the same liquid. This technique appears to be most popular in the USSR, where many measurements ${ }^{143-145}$ have been made with uranium chlorides in binary and ternary molten salts used in uranium electrowinning and electrorefining ceils.

The second most popular method ${ }^{146}$ for measiring surface tension and der zity in a single apparatus is based on a slight modification of the Archimedes float bob. The bob commonly used to measure density of a liquid by buoyancy is modified by adding an accurately machined rod-like protrusion on its bottom. The density of the molten salt can then be determined by measuring the buoyant force on the bob in the usual fashion. The container is lowered and the discontinuity of the indicated weight is noted at the instant of breaking contact between the bob and the liquid. The preferred gecmetry of the bob is a double cone (base to base), with a rod about $5 \mathrm{~mm}$ long by $1 \mathrm{~mm}$ diam extending from the base. The rod must be accurately machined with the face perpendicular to the axis, and the diameter must be known accurately. The material from which the bob is machined must be resistant to corrosion by molten salts and its coefficient of thermal expansion must be known. Oak Ridge has used the Archimedean float for measuring densities of molten salts containing thorium tetrafluoride, but surface tensions were not determined in that work. ${ }^{147}$

3. Viscosity. Only limited viscosity measurements have been made with molten salts containing actinides. Researchers in the USSR have measured viscosities of uranium chlorides in molten chloride mixtures ${ }^{148}$ and thorium fluorides in molten fluoride mixtures ${ }^{149}$ in support of uranium extraction and electrorefining programs and in support of the USSR's fluoride-based reactor program, respectively. The molten salts were contained in cylindrical crucibles suspended in furnaces by torsion wires. No other experimental details were given except that the "torsional vibration" method was used. This apparently is the oscillating container method, which is to be compared with the method of oscillations of an immersed cylinder ${ }^{150}$ and with capillary flow methods. ${ }^{151}$ It is unclear which method is most accurate. Experiments in the Molien Salt Reactor program at Oak Ridge ${ }^{152}$ have used a commercially available coaxial cylinder viscometer for measuring viscosities in molten fluorides. This instrument indicates the torque on the drive shaft of a cylinder immersed in the molten salt when the cylinder is rotated at constant speed on the axis of the cylindrical container. A set of viscosity standards was used to calibrate the apparatus.

\section{ABSORP'TION SPECTRA}

This discussion is limited to measurement techniques of the ultraviolet-visible, and near-infrared absorption spectra of molten actinide salts. The general topic of molten salt spectroscopy is discussed in much greater depth by T. R. Griffiths in a recent publication. ${ }^{153}$

Early work with the intense alpha emitters plutonium, neptunium, and americium used essentially "benchtop" techniques. The risks were acceptable for several reasons. The quantities of actinides were small (milligrams) so that escape of a small fraction of a sample would be serious but not catastrophic, although one must remember that one milligram of plutonium is about 1000 budy burdens. Quartz or borosilicate glass cells were primary containers for the salts, with the spectrophotometer furnace as a secondary container. The spectrophotometers were used in laboratories with favorable air flow to protect personnel from airborne radioactive particles. These conditions made possible many successful studies of highly radioactive molten salts.

The earliest ${ }^{154}$ studies of uranium, plutonium, and neptunium in molten salts were performed with a Beckman DU spectrophotometer in which the cell compartment was replaced by a conling block and a furnace block, which could be heated to $240^{\circ} \mathrm{C}$ by recirculated silicone oil. The solvents were lithium nitrate/potassium nitrate eutectic (mp $132^{\circ} \mathrm{C}$ ) and pyridinium chloride ( $\mathrm{mp} 144^{\circ} \mathrm{C}$ ).

The next evolutionary step was introduction of a higher-temperature $\left(700^{\circ} \mathrm{C}\right)$ furnace $e^{155.156}$ and interchange of the positions of the light source and detector of the Beckmar DU, so only a small portion of the thermal radiation from the furnace passed through the monochromator to the detector. The list of molten salt solvents was then expanded to include lithium chloride/potassium chloride, which was purified by drying in vacuo and sparging wit sydrogen chloride gas. The liquid eutectic was then dripped into carbon tetrachloride to form pellets. Lithium chloride/potassium chloride thus prepared did not etch quartz optical cells or the attached quartz reservoirs that were filled, evacuated, and sealed for observation of the spectra.

I took a different approach to modifying a Beckman DU spectrophotometer for observation of plutonium in molten salt systems. As is illustrated in Fig. 16, 1 removed the light source from the monochromator case and attached it to a furnace containing the optical cells inside a glovebox. Light from the source was transmitted through the furnace containing the optical cells. a 


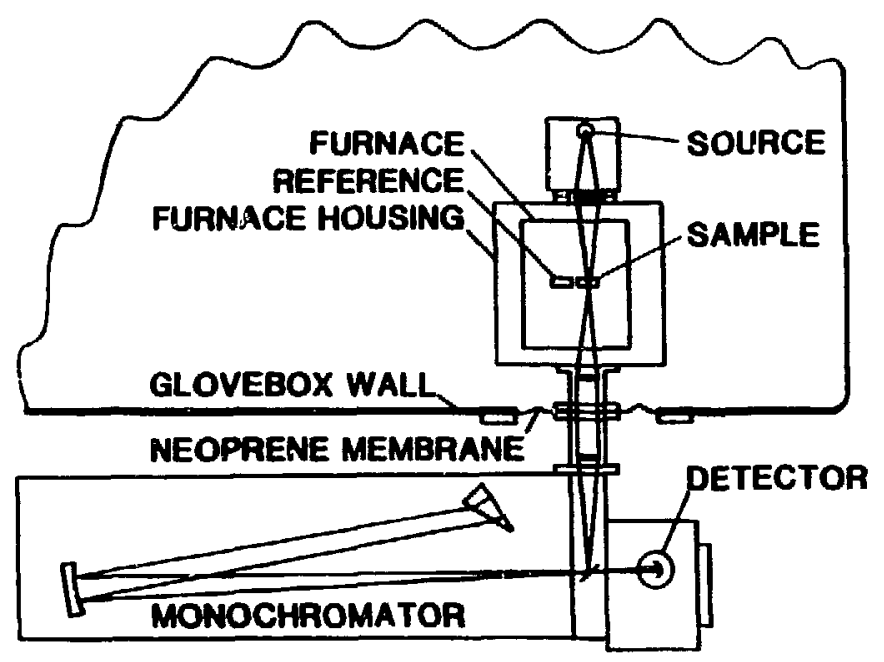

Fig. 16. Spectrophotometer used for studies of molten plutonium salts.

simple lens system in a brass tube, a quartz window in the brass tube at the plane of the glovebox wall, the monochromator, and finally through the original cell compartment to the detector. I maintained the integrity of the alpha enclosure by sealing a flange of the brass tube to the glovebox wall. This technique allowed keeping the fragile plutonium-containing optical cells in the glovebox enclosure. Other techniques have been developed at Los Alamos to accomplish the same objective. The simplest of these is the use of wells (approximately $15 \mathrm{~cm}$ square by $30 \mathrm{~cm}$ deep, with appropriate windows sealed to the sides) attached to the floor of the glovebox in a location such that the cell compartment of the spectrometer can be positioned to enclose it. Heaters and optical cells are placed in the well writh their optical path aligned with the windows.

As more modern spectrophotometers became available, Argonne National Laboratory, Oak Ridge National Laboratory, and Hanford Laboratory replaced the Beckman DU spectrophotometer with the double-beam (Varian) Cary Model $14 \mathrm{H}$ spectrophotometer, which has a lamp-sample-monochromator-detector arrangement that virtually eliminates interference from furnace thermal radiation. Various furnace designs ${ }^{157-160}$ have been developed, one of which permits operation at up to $1450^{\circ} \mathrm{C}$. Silica optical cells are still the most popular for molten salts except fluorides and metal/salt systems, which are incompatible with silica. Windowless cells, such as the "captive liquid" cells described by Young, ${ }^{161}$ were developed fo: these corrosive liquids. Other windowless cells ${ }^{162.163}$ used to support corrosive liquids have been platinum screens, loops, spirals, and tube segments. The major fault of most of these windowless cells is that the effective path length cannot be de- termined accurately. A graptsite cell with diamond windows ${ }^{164}$ has been developed for observing fluorides. The diamond windows (nominally $5 \times 5 \times 1 \mathrm{~mm}$ ) are very expensive and darken unacceptably at $800^{\circ} \mathrm{C}$. The windows are not required to fit tightly because molten fluorides do not wet graphite and, in the absence of a large pressure differential, will not run out through a small orifice because of surface tension.

Other systems for studies of absorption spectra of actinides have used commercial monochromators with supporting optics, choppers, light siurces, and detectors set up on optical tables. ${ }^{14,28} \mathrm{~A}$ new concept in commercial spectrophotometers that may offer versatility needed for observing molten actinide salts is being sold by a new company, Guided Wave, Inc., of Rancho Cordova, Califorsia. ${ }^{30}$ This instrument uses fiber optic light pipes to transmit light to and from the sample, which may be located at some distance (more than $10 \mathrm{~m}$ ) from the spectrophotometer. Other developments in computerized data acquisition and analysis and more intense broad-spectrum light sources should make possible more rapid and accurate measurement of absorption spectra with even smaller furnaces and samples than have been required in the past.

\section{ELFCTROCHEMISTRY}

Studies of the electrochemistry of actinide molten salts have been limited. Electrorefining and electrolysis of thorium, uranium, and plutonium in molten salt systems on the multikilugram scale have already been discussed in Sec. VI.D.1. These processes seem to have been developed with very little basic research. 
Techniques for studying electrochemistry of actinide molten salts are not significantly different from those for studying nonactinides. The general techniques have been described often and much more comprehensively than in this short treatment. ${ }^{165-168}$ Gloveboxes are required for studying the actinides (with the exception of uranium and thorium), but these enclosures are not unique to actinide study. Traces of oxygen and water interfere so severely with electrochemical studies that glovebox enclosures have been used for studies of hygroscopic nonactinide salts. Cells for studies of actinide systems employ the usual materials such as quartz, borosilicate glass, tantalum, and tungsten. The very reactive molten metals cannot be allowed direct contact with quartz or glass and must be contained by tantalum, tungsten, molybdenum, beryllium oxide, thorium oxide, or other nonreactive material. The fluorides are often studied in containers made of platinum, graphite, nickel, or molybdenum and the oxides of thorium, beryllium, or magnesium.

Only conductance and EMF studies will be reported here. Recent condustance measurements have been made almost exclusively on fluorides that may be used in molten salt reactors. ${ }^{19}$ EMF measurements have been made on only a small number of the actinides in chloride systems.

\section{A. Conductance Measurements}

Almost all of the conductance measurements of actinide salts that are reported in the technical journals were made in the USSR. The reports present data but

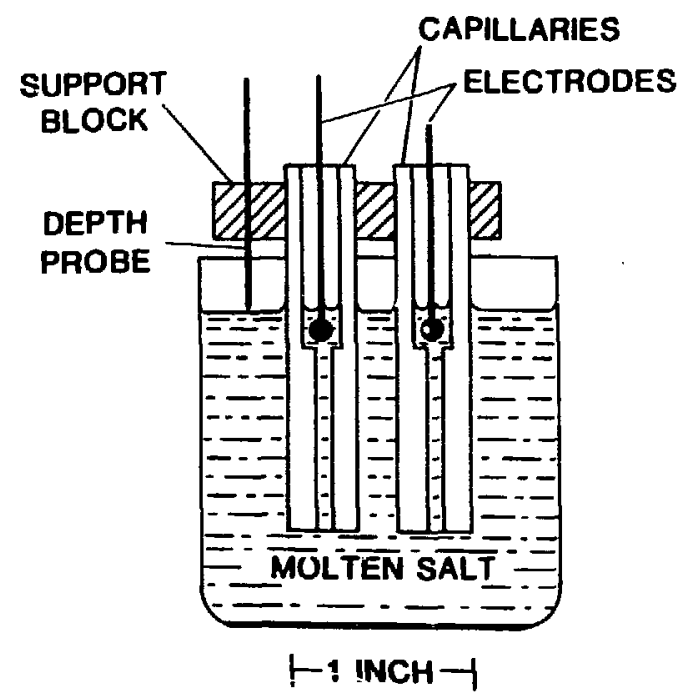

Fig. 17. Capilary cell used for measuring conductance of molten salts. give very little information concerning the techniques. The technique most often cited is the capillary cell method ${ }^{142,169-172}$ described by Janz. Because of the use of the plural "capillaries," one may infer that the capillary technique used is that which employs two capillary tubes (Fig. 17). The portion of the capillaries that dips into the molten salts is about $1-\mathrm{mm}$ i.d. and about 25 $\mathrm{mm}$ long. The upper portion has a larger inside diameter to accommodate electrical connectors. When in use, the bottom of this upper portion must be at a level just beneath the surface of the salt in its crucible. For accurate measurements the capillaries must be held rigidly in a reproducible position. Rods or tubes made of precious or refractory metals maintain electrical contact. The cell constant is determined by observing aqueous or molten salt standards. ${ }^{173}$ The best descriptions of this type of cell recommend that the capillaries be fabricated from single crystal magnesium oxide, but they may also be made of glass, quartz, boron nitride and polycrystalline magnesium oxide, or beryllium oxide. Alternating current frequencies of $1-50 \mathrm{kHz}$ have been used for measurements.

Typical studies that have been reported are (1) thorium tetrafluoride with lithium and sodium fluorides using magnesia capillaries and nickel container and electrodes up to $950^{\circ} \mathrm{C}_{1}^{171}$ (2) uranium, thorium, beryllium, and lithium tern: $r y$ and quaternary fluoride systems using beryllia capillaries and molybdenum electrodes up to $1000^{\circ} \mathrm{C},{ }^{172}$ and (3) uranium and sodium fluoride using polycrystalline magnesia capillaries up to $1170^{\circ} \mathrm{C} .^{174}$

\section{B. Electromotive Force Measurements}

The reported EMF measurements of actinide molten salt systems have been for the determination of thermodynamic quantities such as free energies of formation and activities and for the elucidation of electrode processes and measurement of current efficiencies. Most of the EMF studies at Los Alamos have been for determination of free energies of formation of plutonium compounds. The free energy of formation of plutonium trichloride was determined by using the cell ${ }^{175,176}$

$\mathrm{Pu}(\mathrm{liq}) / \mathrm{PuCl}_{3}-\mathrm{MCl}(\mathrm{liq}) / \mathrm{Cl}_{2}(\mathrm{~g})$,

where $M$ was sodium and potassium. The molten plutonium was contained in a porous thoria crucible and chlorine gas was introduced through a graphite electrode. Another study of plutonium trichloride was made by using the cell ${ }^{177}$

$\mathrm{Pu}-\mathrm{PuCl}_{3}(\mathrm{~s}) / \mathrm{SaCl}_{2}$ (s)/(NaCl-AgCl,Ag(s) . 
Cells with lithium chloride/potassium chloride eutectic as electrolyte were used to study $\mathrm{PuN}, \mathrm{Pu}_{2} \mathrm{C}_{3}, \mathrm{PuC}_{(1-\mathrm{x})}$, $\mathrm{PuRu}_{2}$, and $\mathrm{PuFe}_{2}$ (Ref. 175). One of the unique techniques developed during this work ${ }^{178}$ was formation of a "temporary" liquid plutonium electrode by electrodepositing plutonium from the electrolyte onto a tungsten microelectrode, measuring the EMF, and immediately stripping off the piutonium by electrolysis. This technique alleviates the active metal-container corrosion problem. It was also extended to the uses of a controlled potential to generate a concentration gradient near the electrode surface. ${ }^{179}$ This gradient was then allowed to relax under open circuit conditions and the potential versus time curves were treated theoretically to calculate parameters for describing the system. The method was applied in determining thermodyramic properties of binary laves phase compounds of plutonium with iron, ruthenium, and osmium. ${ }^{180}$

Among the many electrochemical studies by Inman at Imperial College (London) are EMF studies of uranium and thorium in molten chloride systems. During studies of the cell ${ }^{181.182}$

\section{$\mathrm{U} / \mathrm{UCl}_{3}, \mathrm{LiCl}-\mathrm{KCl} / \mathrm{LiCl}-\mathrm{KCl}, \mathrm{AgCl} / \mathrm{Ag}$}

and the analogous thorium cell, ${ }^{183}$ activities in the salt phase were determined and mechanisms of electrode reactions were elucidated. Unique techniques in this work included preparation and addition of hygroscopic salts to the cell without exposure to the atmosphere, and use of a silver/silver chloride reference electrode enclosed by a quartz diaphragm.

Workers at Argonne have reported on two series of EMF studies of molten actinide salts. In one of these ${ }^{184}$ the cell was

$$
\mathrm{U} / \mathrm{UCl}_{3}, \mathrm{LiCl}-\mathrm{KCl} / \mathrm{LiCl}-\mathrm{KCl}, \mathrm{AgCl} / \mathrm{Ag} \text {. }
$$

Silver chloride/silver electrodes were formed in situ by electrolysis using a silver wire anode and auxiliary platinum cathode. During this work, uranium wire corroded slowly in molten lithium/potassium chlnride eutectic contained in Pyrex, whereas corrosion did not occur when the container was sapphire.

The other work reported from Argonne was determination of thermodynamic quantities of a series of actinide metal alloys. A typical cell used in this series was

$$
\mathrm{U}(\mathrm{s}) / \mathrm{UCl}_{3}, \mathrm{LiCl}-\mathrm{KCl}(\text { liq)/U-Cd(liq) , }
$$

where the uranium electrode was a solid rod and the uranium/cadmium was a liquid in an alumina or tantalum crucible. The alloys were uranium/cadmium, ${ }^{185}$ plutonium/zinc, ${ }^{186}$ plutonium/cadminum, ${ }^{18}$ tunium/cadmium. ${ }^{188}$ The free energies of formation and other thermodynamic quantities of several intermetallic compounds were calculated, as were activity coefficients of the actinides in these alloys. These might be valuable in predicting separations from impurities by use of such alloys as anodes during electrorefining.

\section{SUMMARY}

The study of actinides in molten salt systems is interesting and challeuging. Many areas remain to be explored. The techniques are in many ways similar to those used in studies of other active metal elements such as the alkaline earths and rare earths, but new and modified tecnniques have been introduced to meet the challenge of intense radioactivity of most of them. Many of the challenges in this field are regulatory, that is, there are regulations concerning security, accountability, personnel safety, and environmental protection imposed by many regulatory agencies, but it should be recognized that these regulatory agencies and their parent governments (rather than private corporations) have supported work with the actinides. Indeed, many of the techniques now applied to work with nonactinides in private industries were developed in laboratories established to study actinides.

\section{REFERENCES}

1. National Research Council Committee on Nuclear and Alternative Energy Systems, Energy in Transition, 1985-2010 (W. H. Freeman and Co., San Francisco, 1980), pp. 128-160.

2. E. M. Levin, C. R. Robbins, and H. F. McMurdie, Phase Diägrams for Ceramists, M. K. Reser, Ed. (The American Ceramic Society Inc., Columbus, Ohio, 1964).

3. E. M. Levin, C. R. Robbins, and H. F. McMurdie, Phase Diagrams for Ceramists, 1969 Supplement, M. K. Reser, Ed. (The American Ceramic Society, Inc., Columbus, Ohio, 1969).

4. E. M. Levin and H. F. McMurdie, Phase Diagrams for Ceramists, 1975 Supplement, M. K. Reser, Ed. (The American Ceramic Society, Inc., Columbus, Ohio, 1975).

5. R. S. Roth, T. Negas, and L. P. Cook, Phase Diagrams for Ceramists, Volume IV, G. S. Smith, Ed. (The American Ceramic Society, Inc., Columbus, Ohio, 1981).

6. J. D. Farr, A. L. Giorgi, M. G. Bowman, and R. K. Money, J. Inorg. Nucl. Chem. 18, $42-47$ (1961). 
7. D. A. Collins, J. Hillary, J. S. Nairn, and G. M. Phillips, J. Inorg. Nucl. Chem. 24, 441-459 (1962).

8. D. C. Stewart, Handling Radioactivity (John Wiley and Sons, New York, 1981).

9. D. C. Stewart, "Technologies of Handling Highly Active Beta- and Gamma-Emitting Material," in Techniques of Inorganic Chemistry, Vol. III, H . B. Ionassen and A. Weissberger, Eds. (John Wiley and Sons, New York, 1963), pp. 167-75.

10. IAEA Advisory Group, Manual on Safety Aspects of the Design and Equipment of Hot Laboratories, Safety Series No. 30 (International Atomic Energy Agency, Vienna, 1981).

11. United Nations, Second United Nations International Conference on the Peaceful Uses of Atomic Energy, Vol. 17, Processing Irradiated Fuels and Radioactive Materiais (United Nations, Geneva, 1958), pp. 352-494.

12. P. J. Peterson, R. L. Thomas, and J. L. Green, "Hot Cells for "lutonium Reactor Fuel Research," Second United Nations Conference on the Peaceful Uses of Atomic Energy, Vol. 17, Processing Irradiated Fuels and Radioactive Materials (United Nations, Geneva, 1958), pp. 664-667.

13. G. N. Walton, Ed., Gloveboxes and Shielded Cells for Handling Radioactive Materials, Procedings of the Symposium on Glovebox Design and Operation (Academic Press. New York, 1958).

14. C. D. Calkins and P. Schall, "Radiation Damage-Miscellaneous Materials," in Reacior Har:dbook, Second Edition. Vol. 1, Materials, C. R. Tipton, Ed. (Interscience Publishers, Inc., New York, 1960), pp. 74-83.

15. "How Radiation Affects Materials, A Special Report," Niecleonics 14 (9), 53-88 (1956).

16. W. R. Grimes and D. R. Cuneo, "Molten Salts as Reactor Fuels," in Reactor Handbook, Second Edition, Vol. 1, Materials, C. R. Tipton, Ed. (Interscience Publishers, Inc., New York, 1960), pp. 425-476.

17. W. R. Grimes, D. R. Cuneo, F. F. Blakenship, G. W. Keilholtz, H. F. Poppendiek, and M. T. Robinson, "Chemical Aspects of Molten-Fluoride-Salt Reactor Fuels," in Fluid Fuel Reactors, J. A. Lane, H. G. MacPherson, and F. Maslan, Eds. (AddisonWesley, Reading, Massachusetts, 1958), pp. 569-594.
18. D. M. Gruen, R. L. McBeth, J. Kooi, and W. T. Carnall, Ann. N. Y. Acad. Sci. 79, $941-949$ (1960).

19. J. W. Koger, Corrosion - NACE 29, pp. 115-122 (1)73).

20. A. Glassner, "The Thermochemical Properties of the Oxides, Fluorides, and Chlorides to $2500^{\circ} \mathrm{K}$," Argonne National Laboratory report ANL-5750 (1957).

21. D. C. Christensen and L. J. Mullins, "Plutonium Metal Production and Purification at Los Alamos," in Plutonium Chemistry, W. T.Carnall and G. R. Choppin, Eds. (American Chemical Society, Washington, D.C., 1983), pp. 409-431.

22. G. S. Perry, L. G. Macdonald, and S. D. Wilcox, "Contamination of Molten Salts by Crucible Materials," HCTD technical memorandum 1/84, Atomic Weapons Research Establishment, Aldermaston, England (June 1984).

23. C. E. Baldwin, "Pyrochemical Development at Rocky Flats for Recovery and Purification of Plutonium," in Actinide Recovery from Waste and Low-Grade Sources, J. D. Navratil and W. W. Schulz, Eds. (Harwood Academic Publishers, New York, 1982). pp. 56-60.

24. B. B. Cunningham, "Submicrogram Methods Used in Studies of the Synthetic Elements," in Submicrogram Experimentation, N. D. Cheronis, Ed. (Interscience Publishers, New York, 1961), pp. 69-87.

25. J. R. Peterson, "Technique: of Microchemistry and Their Application to Some Transcurium Elements at Berkeley and Oak Ridge," in Lanthanide and Actinide Chemistry and Spectroscopy, N. M. Edelstein, Ed. (American Chemical Society, Washington, D.C., 1980), pp. 221-238.

26. J. N. Stevenson and J. R. Peterson, Microchem. J. 20, 213-220 (1975).

27. E. F. Westrum, Jr., and LeRoy Eyvring, J. Am. Chem. Soc. 73, 3399-3400 (1951).

28. J. L. Green and 2. B. Cunningham, Inorg. Nucl. Chem. Lett. 2, 365-371 (1966).

29. J. P. Young, K. L. Vander Sluis, G. K. Werner, J. R. Peterson, and M. Noe, J. Innrg. Nucl. Chem. 37, 2497-2501 (1975). 
30. Guided Wave, Inc., The Optical Waveguide Spectrum Analyzer (Guided Wave Inc., Rancho Cordova, California, 1984).

31. D. B. McWhan, B. B. Cunningham, and J. C. Wallmann, J. Inorg. Nucl. Chem. 24, 1025-1038 (1962).

32. D. R. Stephens, H. D. Stromberg, and E. M. Liliey, J. Phys. Chem. Solids 29, 815-821 (1968).

33. L. Grainger, $L \cdot$ znium and Thorium (George Newness, Ltd., London, 1958), pp. 46-73.

34. F. L. Cuthbert, Thorium Production Technology (Addison-Wesley, Reading, Massachusetts, 1958), pp. 50-96.

35. F. A. Cotton and G. Wilkison, Advanced Inorganic Chemistry; A Comprehensive Text Third Ed. (Interscience Pub., New York, 1972), pp. 1096-1098.

36. D. O. Campbell, "Studies of the Behavior of Protactinium in Sulfuric Acid," in Physico-Chimie du Protactinium, Colloques Internationaux, Orsay, July 2-8, 1965 (Centre National de la Recherche Scientifique, Paris, 1966), pp. 209-223.

37. H. W. Kirby, "Hydrolitic Separation of Protactinium," in Physico-Chimie du Protactinium, Colloques Internationaux, Orsay, July 2-8, 1965 (Centre National de la Recherche Scientifique, Paris, 1966), pp. 283-291.

38. L. Grainger, Uranium and Thorium (George Newness, Ltd., London, 1958), pp. 1-45.

39. J. C. Burger and J. McN. Jardine, "Canadian Refining Practice in the Production of Uranium Trioxide by Solvent Extraction with Tributyl Phosphate," Second United Nations International Conference on the Peaceful Uses of Atomic Energy, Vol. 4, Production of Nuclear Materials and Isotopes (United Nations, Geneva, 1958), pp. 3-9.

40. R. Gelin, H. Mogard, and B. Nelson, "Refining of Uranium Concentrate and Production of Uranium Oxide and Metal," Second United $\mathrm{Na}$ tions Conference on the Peaceful Uses of Atomic Energy, Vol. 4, Production of Nuclear Materials and Isotopes (United Nations, Geneva, 1958), pp. 36-39.

41. W. W. Schulz and G. E. Benedict, Neptunium-237 Producticn and Recovery [US Atomic Energy Commission (now DOE) Technical Information Center, Oak Ridge, Tennessee, 1972)].
42. L. W. Gray, G. A. Bumey, T. W. Wilsen, and J. M. McKibbben, "Recovery of Americium-Curium from High-Activity Waste Concentrate by In-Canyon-Tank Precipitation as Oxylates," in TransFlutonium Elements-Production and Recovery, J. D. Navratil and W. W. Schulz, Eds. (American Chemical Society, Washington, D. C., 1981), pp. 223-242.

43. P. C. Doto, L. E. Bruns, and W. W. Schulz, "Solvent Extraction Process for Recovery of Americium-241 at Hanford," in Transplutonium Elements - Production and Recovery, J. D. Navratil and W. W. Schulz, Eds. (American Cuemical Society, Washington, D. C., 1981), pp. 109-129.

44. L. W. Gray, G. A. Bumey, T. A. Reilly, T. W. Wilson, and J. M. McKibben, "Recovery of Americium-241 from Aged Plutonium Metal," Transplutonium Elements - Production and Recovery, J. D. Navratil and W. W. Schulz, Eds. (American Chemical Society, Washington, D. C., 1981), pp. 93-108.

45. H. D. Ramsey, D. G. Clifton, S. W. Hayter, R. A. Penneman, and E. L. Christensen, in "Status of Americium-241 Recovery and Purification at Los Alamos National Laboratory," Transplutonium Elements - Production and Recovery, J. D. Navratil and W. W. Schulz, Eds. (American Chemical Society, Vashington, D. C., 1981), pp. 75-91.

46. J. B. Knighton, P. G. Hagan, J. D. Navratil, and G. H. Thompson, "Status of Americium-241 Recovery at Rocky Flats Plant," in Transplutonium Elements - Production and Recovery, J. D. Navratil and W. W. Schulz, Eds. (American Chemical Society, Washington, D. C., 1981), pp. 53-74.

47. M. S. Coops, J. B. Knighton, and L. J. Mullins, "Pyrochemical Processing of Plutonium," in Plutonium Chemistry, W. T. Carnall and G. R. Choppin, Eds. (American Chemical Society, Washington, D. C., 1983), pp. 386-398.

48. C. Keller, The Chemistry of the Transuranium Elements (Verlag Chemie GmbH, Weinheim/Bergstrasse, Germany, 1971), p. 532.

49. T. C. Gorrell, Trans. Am. Nucl. Soc. 14, 343-344 (1971).

50. K Buijs, F. Maino, W. Muller, J. Reul, and J. Cl. Toussaint, "The Separation and Purification of 
Americium and Curium on the Multigram Scale," J. Inorg. Nucl. Chem., Supplement 1976 (Moscow Symposium on the Chemistry of Transuranium Elements), V. 1. Spitsyn and J. J. Katz, Eds. (Pergamon Press, New York, 1976), pp. 209-213.

51. L. J. King, J. E. Bigelow, and E. D. Collins, "Experience in the Separation and Purification of Transplutonium Elements in the Transuranium Processing Plant at Oak Ridge National Laboratory," in Transplutonium Elements - Production and Recovery, J. D. Navratil and W. W. Schulz, Eds. (American Chemical Society, Washington, D. C., 1981), pp. 133-145.

52. F. T. Hagemann, "The Chemistry of Actinium," in The Actinide Elements, G. T. Seaborg and J. J. Katz, Eds. (McGraw-Hill, New York, 1954), pp. 14-44.

53. F. L. Cuthbert, Thorium Production Technology (Addison-Wesley, Reading, Massachusetts, 1958), p. 152 .

54. L. I. Katzin, "The Chemistry of Thorium," in The Actinide Elements, G. T. Seaborg and J. J. Katz, Eds. (McGraw-Hill, New York. 1954), p. 82.

55. F. L. Cuthbert, Thorium Production Technology (Addison-Wesley, Reading, Massachusetts, 1958), p. 160.

56. A. H. Roberson, Preparation of Thorium Chloride from Thorium Oxalate, U. S. Bureau of Mines Circular 101 (1956).

57. W. Fischer, R. Gewehr, and $H$. Wingchen, $Z$. Anorg. Allg. Chem. 242, 161-187 (1939).

58. L. B. Asprey, F. H. Kruse, and R. A. Penneman, Inorg. Chem. 6, 544-548 (1967).

59. P. A. Sellers, S. Fried, R. E. Elson, and w. H. Zachariasen, J. Am. Chem. Soc. 76, 5935-5938 (1954).

60. L. Stein, Inorg. Chem. 3, 995-1001 (1964).

61. D. Brown and P. J. Jones, J. Chem. Soc. (A), 719-723 (1967).

62. M. E. Hendricks, E. R. Jones, J. A. Stone, and D. G. Karraker, J. Chem. Phys. 55, 2993-2997 (1971).

63. D. Brown and P. J. Jones, J. Chem. Soc. (A), 874-878 (1966).
64. D. Brown, J. Hill, and C. E. F. Rickard, J. Chem. Soc. (A), 476-480 (1970).

65. D. Brown and P. J. Jones, J. Chem. Soc. (A), 262-264 (1966).

66. D. Brown, J. F. Easey, and P. J. Jones, J. Chem. Soc. (A), 1698-1702 (1967).

67. H. R. Hoekstra and J. J. Katz, "The Chemistry of Uranium," in The Actinide Elements, G. T. Seaborg and J. J. Katz, Eds. (McGraw-Hill, New York, 1954), pp. 147-148.

68. J. J. Katz and E. Rabinowitch, The Chemistry of Uranium - Part I (McGraw-Hill, New York, 1951), p. 361.

69. F. S. Patton, J. M. Googin, and W. L. Griffith, Enriched Uranium Processing (Pergamon Press, New York, 1963), pp. 63-64.

70. S. Fried and N. Davidson, J. Am. Chem. Soc. 70 , 3539-3547 (1948).

71. L. E. Trevorrow, T. J. Gerding, and M. J. Steindier, J. Inorg. Nucl. Chem. 30, 2671-2677 (1968).

72. J. G. Reavis, K. W. R. Johnson, J. A. Leary, A. N. Morgan, A. E. Ogard, and K. A. Walsh, "The Preparation of Plutonium Halides for Fused Salt Studies," in Extractive and Physical Metallurgy of Plutonium and Its Alloys, W. D. Wilkinson, Ed. (Interscience Publishers, New York, 1960), pp. 89-100.

73. M. J. Steindler, D. V. Steidl, and R. K Steunenberg, Nucl. Sci. Eng. 6, 333-340 (1959).

74. F. Hagemann, B. M. Abraham, N. R. Davidson, J. J. Katz, and I. Sheft, in The Transuranium Elements Research Papers, G. T. Seaborg, J. J. Katz, and W. M. Manning, Eds. (McGraw-Hill, New York, 1949), pp. 957-963.

75. S. Fried, J. Am. Chem. Soc. 73, 416-418 (1951).

76. W. V. Conner, J. Less-Common Metals 25 , 379-384 (1971).

77. R. D. Baybarz, J. Inorg. Nucl. Chem. 35, 483-487 (1973).

78. J. H. Burns and J. ?. Peterson, Acta Crystallogr. Sect. B 26, 1885-1857 (1970). 
79. R. G. Pappalardo, W. T. Carnall, and P. R. Fieids, J. Chem. Phys. 51, 1182-1200 (1969).

80. L. B. Asprey, T. K. Keenan, and F. H. Kruse, Inorg. Chem. 4, 985-986 (1965).

81. R. D. Baybarz, L. B. Asprey, C. E. Strouse, and E. Fukushima, J. Inorg. Nucl. Chem. 34, 3427-3431 (1972).

82. L. B. Asprey, T. K. Keenan, and F. H. Kruse, Inorg. Chem. 3, 1137-1 140 (1964).

83. W. W. Schulz, The Chemistry of Americium, TID-26971 [US Energy Research and Development Administration (now DOE) Technical Information Center Oak Ridge, Tennessee, 1976], pp. 151-159.

84. L. B. Asprey, F. H. Ellinger, S. Fried, and W. H. Zachariasen, J. Am. Chem. Soc. 79, 5825 (1957).

85. J. H. Simons and L. P. Block, J. Am. Chem. Soc. 61, 2962-2966 (1939).

86. R. L. Farrar, Jr., and E. J. Barber, "Some Considerations in the Handling of Fluorine and the Chlorine Fluorides," Report K/ET-252, Enrichment Division, Oak Ridge Gaseous Diffusion Plani report K/ET-252 (1979).

87. J. G. Reavis and J. A. Leary, J. Inorg. Nucl. Chem. 28, 1205-1208 (1966).

88. C. W. Koch and B. B. Cunningham, J. Am. Chem. Soc. 76, 1470 (1954).

89. B. B. Cunningham, "Preparation and Properues of the Compounds of Plutonium," in The Actinide Elements, G. T. Seaborg and J. J. Katz, Eds. (McGraw-Hill, New York, 1954), p. 390.

90. D. Brown and J. F. Easey, J. Chem. Soc. $(A)$, 3378-3381 (1970).

91. J. Hauck. J. Inorg. Nucl. Chem. 36, 2291-2298 (1974).

92. C. W. Bjorklund, J. G. Reavis, J. A. Leary, and K. A. Walsh, J. Phys. Chem. 63, 1774-1777 (1959).

93. H. A. Laitinen, W. S. Ferguson, and R. A. Osteryoung, J. Electrochem. : $x$. 104, 516-520 (1957).

94. D. L. Maricle and D. N. Hume J. Electrochem. Soc. 107, 354-356 (1960).
95. S. Fried, E. F. Westrum, H. L. Baumbach, and P. L. Kirk, J. Inorg. Nucl. Chem. 5, 182-189 (1958).

96. J. N. Stevenson and J. R. Peterson, J. Microchem. 20, 213-220 (1975).

97. F. L. Cuthbert, Thorium Production Technology (Addison-Wesley, Reading, Massachusetts, 1958), p. 180.

98. R. D. Baker, "Preparation of Plutonium Metal by the Bomb Method," Los Alamos Scientific Laboratory report LA-473 (May 1946).

99. L. Grainger, Uranium and Thorium, (George Newness, Ltd., London, 1958), p. 38.

100. J. G. Reavis, J. A. Leary, and K. A. Walsh, U. S. Patent No. 2,886,410, May 1959.

101. D. C. Christensen and L. J. Mullins, "Present Status of Plutonium Metal Production and Purification at Los Alamos-1982," Los Alamos National Laboratory report LA-9674-MS (June 1983).

102. J. W. Marden, Trans. Electrochem. Soc. 66, 39-47 (1934).

103. L. Grainger, Uranium and Thorium (George Newness, Ltd., Lon'sn, 1958), pp. 62-63.

104. B. Blumenthal and B. Brodsky, "The Preparation of High Purity Plutonium," in Plutonium 1960, E. Grison, W. B. H. Lord, and R. D. Fowler, Eds. (Cleaver-Hume Press, Ltd., London, 1961), pp. 171-186.

105. L. J. Mullins, A. N. Morgan, S. A. Apgar III, and D. C. Christensen, "Six-Kilogram Scale Electrorefining of Plutonium Metal," Los Alamos National Laboratory report LA-9469-MS (September 1982).

106. L. J. Mullins, A. J. Beaumont, and J. A. Leary, J. Inorg. Nucl. Chem. 30, 147-156 (1968).

107. R. K. Steunenberg, R. D. Pierce, and L. Burris, "Pyrometallurgical and Pyrochemical Fuel Processing Methods," in Progress in Nuclear Energy, Series III, Process Chemistry, Vol. 4, C. E. Stevenson, E. A. Mason and A. T. Gresky, Eds. (Pergamon Press, New York, 1970), pp. 482-486.

108. J. K. Bates, L. J. Jardine, and M. Krumpelt, "A. Nonaqueous Reprocessing Method for ThoriumBased Fuels," in Actinide Separations, J. D. 
Navratil and W. W. Schulz, Eds. (American Chemical Society, Washington, D. C., 1980), pp. 207-217.

109. J. Johnson, J. Nucl. Mater. 51, 163-177 (1974).

110. I. Johnson, J. B. Knighton, and R. K. Steunenberg, Trans. Met. Soc. AIME 236, 1241-1246 (1966).

111. C. J. Barton, H. A. Friedman, W. R. Grimes, H. Insley, R. E. Moore, and R. E. Thoma, J. Am. Ceram. Soc. 41, 63-69 (1958).

112. C. J. Barton, W. R. Grimes, H. Insley, R. E. Moore, and R. E. Thoma, J. Phys. Chem. 62. 665-676 (1958).

113. R. E. Thoma, H. Insley, H. A. Friedman, and C. F. Weaver. J. Phys. Chem. 64, 865-870 (1960).

114. C. F. Weaver, R. E. Thoma, H. Insley, and H. A. Friedman, J. Amer. Ceram. Soc. 43, 213-218 (1960).

115. K. W. R. Johnson, M. Kahn, and J. A. Leary, J. Phys. Chem. 65, 2226-2229 (1961).

116. R. Benz and R. M. Douglass, J. Phys. Chem. 65, 1461-1463 (1961).

117. R. Benz, M. Kahn, and J. A. Leary, J. Phys. Chem. 63, 1983-1984 (1959).

118. M. Pages and W. Freundlich, J. Inorg. Nucl. Chem. 34, 2797-2801 (1972).

119. V. I. Spitsyn, A. N. Pokrovskii, N. S. Afonskii, and V. K. Trunov, Dokl. Akad. Nauk, SSSR 188, 1065-1068 (1969) (Plenum Publishing Corp., New York, translation, pp. 825-827).

120. N. N. Bushnev and V. K. Trunov, Radiokhimiva $12,411-412(1970)$

121. J. G. Reavis, G. R. Brewer, D. B. Court, and J. W. Schulte, "A Differential Thermal Analysis Apparatus for Observation of Irradiated PlutoniumContaining Reactor Fuels," Nineteenth Conf. on Remote Systems Technology (American Nuclear Society, La Grange Park, Illinois, 1971), pp. 112-117.

122. B. Weinstock, E. E. Weaver, and J. G. Malm, $J$. Inorg. Nucl. Chem. 11, 104-114 (1959).

123. A. E. Florin, I. R. Tannenbaum, and J. F. Lemons, J. Inorg. Nucl. Chem. 2, 368-379 (1956).
124. C. J. Mandleberg, H. K. Rae, R. Hurst, G. Long, D. Davies, and K. E. Francis, J. Inorg. Nucl. Chem. 2, 358-367 (1956).

125. H.S. Young and H. F. Grady, "Physical Constants of Uranium Tetrachloride," in Chemistry of Uranium, Collected Papers, TID-5290, Book 2, J. J. Katz and E. Rabinowitch, Eds. [US Atomic Energy Commission (now DOE) Technical Information Service, Oak Ridge, Tennessee, 1958],pp. 749-756.

126. W. H. Rodebush and A. L. Dixon, Phys. Kev. 26, $851-858$ (1925).

127. S. Langer and F. F. Blankenship, J. Inorg. Nucl. Chem. 14, 26-3! (1960).

128. A. J. Darnell and F. J. Keneshea, Jr., J. Phys. Chem. 62, 1143-1145 (1958).

129. S. Cantor, R. F. Newton, W. R. Grimes, and F. F. Blankenship, J. Phys. Chem. 62, 96-99 (1958).

130. O. Johnson, T. Butler, and A. S. Newton, "Preparation, Purification and Properties of Anhydrous Uranium Chlorides," in Chemistry of Uranium, Collected Papers, TID-5290, Book 1, J. J. Katz and E. Rabinowitch, Eds. [US Atomic Energy Commission (now DOE) Technical Information Service, Oak Ridge, Tennessee, 1958], pp. 1-28.

131. R. Benz, J. Inorg. Nucl. Chem. 24, 1191-1195 (1962).

132. R. Kent, High Temp. Sci. 1, 169-175 (1969).

133. T. E. Phipps, G. W. Sears, R. L. Seifert, and O. C. Simpson, J. Chem. Phys. 18, 713-723 (1950).

134. T. E. Phipps, G. W. Sears, and O. C. Simpson. J. Chem. Phys. 18, 724-734 (1950).

135. N. D. Erway and O. C. Simpson, J. Chem. Phys. 18, 953-957 (1950).

156. S. C. Carniglia and B. B. Cunningham, J. Am. Chem. Soc. 77, 1451-1453 (1955).

137. J. W. Ward, R. W. Ohse, and R. Reul, J. Chem. Phys. 62, 2366-2372 (1975).

138. J. W. Ward, P. D. Kleinschmidt, R. G. Haire, and D. Brown, "Vapor Pressure and Thermodynamics of Actinide Metals," in Lanthanide and Actinide Chemistry and Spectroscopy, N. M. Edelstein, Ed. 
(American Chemical Society, Washington, D. C., 1980), pp. 199-220.

139. M. H. Bradbury and R. W. Ohse, J. Chem. Phys. 70, 2310-2314 (1979).

140. Y. Umetsu, M. Kawada, E. Nakamura, and T. Ejima, J. Japan Inst. Met. 37, 1139 (1973) [English translation 16, 271-279 (1975)].

141. D. A. Nissen and R. W. Carlsten, J. Electrochem. Soc. 121, 500-505 (1974).

142. G. J. Janz, U. Krebs, H. F. Siegenthaler, and R. P. T. Tomkins, J. Phys. Chem. Ref. Dala 1, 589 (1972).

143. V. N. Desyatnik, S. F. Katyshev and S. P. Raspopin, At. Energ. 42, 99-103 (1977) (Plenum Publishing Corp., New York, translation, pp. 108-111).

144. V. N. Desyatnik and S. F. Katyshev, Zh. Fiz. Khim. 55, 2888-2892 (1981) (The British Library, Letchworth, Herts, translation, pp. 1641-1644).

145. V. N. Desyatnik and S. F. Katyshev, Zh. Fiz Khim 56, 203-205 (1982) (The British Library, Letchworth, Herts, translation, pp. 125-127).

146. G. J. Janz and M. R. Lorenz, Rev. Sci. Instrum. 31 , 18-22(1960).

147. S. Cantor, D. G. Hill, and W. T. Ward, Inorg. NuCl. Chem. Lett. 2, 15-18 (1966).

148. S. F. Katyshev, Yu. F. Chervinskii, and V. N. Desyatnik, At. Energ. 53, 108-109 (1982) (Plenum Publishing Corp., New York, translation, pp. 565-566).

149. Yu. F. Chervinskii, V. N. Desyatnik, and A. I. Nechaev, Zh. Fiz. Khim. 56, 1946-1949 (1982) (The British Library, Letchworth, Herts, translation, pp. 1189-1190).

150. K. Thorkelp and H. A. Oye, J. Phys. [E] 12, 875-885 (1979).

151. G. J. Janz, U. Krebs, H. F. Siegenthaler, and P. T. Tomkins, J. Phys. Chem. Ref. Data 1, 588 (1972).

152. C. T. Moynihan and S. Cantor, J. Chem. Phys. 48, 115-119(1968).

153. T. R. Griffiths, "Molten Salt Speciroscopy," in Molten Salt Techniques, Vol. 2, D. G. Lovering and R. J. Gale, Eds. (Plenum Press, New York. 1984), pp. 79-136.

154. D. M. Gruen, J. Inorg. Nucl. Chem. 4, 74-76 (1957).

155. D. M. Gruen and R. L. McBeth, J. Inorg. Nucl. Chem. 9, 290-301 (1959).

156. D. M. Gruen, S. Fried, P. Graf, and R. L. McBeth, "The Chemistry of Fused Salts," Second United Nations International Conference on Pecieful Uses of Atomic Energy, Vol. 28, Basic Chemistry in Nuclear Energy (United Nations, Geneva, 1958), pp. 112-1?4.

157. D. M. Gruen, Quarterly Reviews, Chem. Soc. 19. 349-368 (1965).

158. C. R. Boston and G. P. Smith, Rev. Sci. Instrum. 36, 206-208 (1965).

159. C. R. Boston and G. P. Smith, J. Phys. (E/ 1969 Senes 2, Vol. 2, 543-546.

160. J. R. Morrey and A. W. Madsen, Rev. Sci. Instr:ım. 32, 799-801 (1961).

161. J. P. Young, Anal. Chem. 36, 390-392 (1964).

162. J. P. Young and J. C. White, Anal. Chem. 31, 1892-1895 (1959).

163. J. Greenberg and L. J. Hallgren, Rev. Sci. Instrum. 31, 444-445 (1960).

164. L. M. Toth, J. P. Young, and G. P. Smith, Anal. Chem. 41, 683-685 (1969).

165. V. E. Norvell and G. Mamantov, "Spectroelectrochemistry," in Molten Salt Techniques, Vol. I, D. G. Lovering and R. J. Gale, Eds. (Plenum Press. New York, 1983), pp. 151-176.

166. H. A. Laitinen and R. A. Osteryoung. "Electrochemistry in Molten Salts," in Fused Salts. B. R. Sundheim, Ed. (McGraw Hill, New York. 1964), pp. 255-300.

167. R. W. Laity, "Electrodes in Fused Salt Systems," in Reference Electrodes, D. J. G. ives and G. J. Janz, Eds. (Academic Press, New York, 1961), pp. 524-606.

168. F. Lantelme, D. Inman, and D. G. Lovering, "Electrochemistry-1," in Molten Salt Techniques, 
Vol. 2, D. G. Lovering and R. J. Gale, Eds. (Plenum Press, New York, 1984), pp. 137-220.

169. G. J. Janz and M. R. Lorenz, Rev. Sci. Instrum. 32, 130-133 (1961).

170. V. N. Desyatnik, A. P. Koverda, G. P. Bystrai, and V. I. Kolontyr, Zh. Prikl. Khim. 52, 316-319(1979) (Plenum Publishing Corp., New York, translation, pp. 288-290).

171. V. N. Desyatnik, A. P. Koverda, N. N. Kurbatov, and V. V. Bystrov, At. Energ. 49, 129-130 (1980) (Plenum Publishing Corp., New York, translation, pp. 583-585).

172. V. N. Desyatnik, A. P. Koverda, N. N. Kurbatov, and V. V. Bystrov, At. Energ. 50, 141-143 (1981) (Plenum Publishing Corp., New Yor:-, translation, pp. 134-136).

173. G. J. Janz, J. Phys. Chem. Ref. Data 9, 791-829 (1980).

174. V. N. Desyatnik, A. P. Koverda, and N. N. Kurbatov, Zh. Fiz. Khim. 55, 3128-3130 (1981) (The British Library, Letchworth, Herts, translation, pp. 1782-1783).

175. R. Benz and J. A. Leary, J. Phys. Chem. 65, 1056-1058 (1961).

176. R. Benz, J. Phys. Chern. 65, 81-84 (1961).

177. G. M. Campbell, L. J. Mullins, and J. A. Leary, "Thermodynamic Properties of Plutonium Compounds by EMF Techniques," Symposium of the Thermodynamics of Nuclear Materinls with Emphasis on Solution Systems (IAEA, Vienna, 1967), pp. 75-88.
178. G. M. Campbell, J. Phys. Chem. 73, 350-355 (1969).

179. G. M. Campbell, J. Electronanal. Chem 47, 387-393 (1973).

180. G. M. Campbell, "The Thermodynamic Properties of the Binary Laves Phase Compounds of Plutonium with the Group VIIIa Metals," in Plutonium 1975 and Other Actinides, H. Blank and R. Linder, Eds. (North-Holland, Amsterdam, 1976), pp. 95-104.

181. D. Inman, G. J. Hills, L. Young, and J. O'M. Bockris, Trans. Faraday Soc. 55, 1904-1914, (1959).

182. D. Inman and J. O'M. Bockris, Can. J. Chem. 39, 1161-1163 (1961).

183. D. Inman, G. J. Hills, L. Young, and J. O'M. Bockris, Ann. N. Y. Acad. Sci. 79, 803-829 (1960).

184. D. M. Gruen and R. A. Osteryoung, Ann. N. Y. Acad. Sci. 79, 897-907 (1960).

185. I. Johnson and H. M. Feder, Trans. Met. Soc. AIME 224, 468-473 (1962).

186. I. Johnson and M. G. Chasanov, J. Inorg. Nucl. Chem. 26, 2059-2067 (1964).

187. I. Johnson, M. G. Chasanov, and R. M. Yonco, Trans. Met. Soc. AIME 233, 1408-1414 (1965).

188. M. Krumpelt, I. Johnson, and J. J. Heiberger, Met. Trans. 5, 65-70 (1974). 